\title{
In vivo Evidence for Brain Region-Specific Molecular Interactions Between Cannabinoid and Orexin Receptors
}

\author{
Hye Ji J. Kim", Ayat Zagzoog1, Anna Maria Smolyakova', Udoka C. Ezeaka1, \\ Michael J. Benko ${ }^{1}$, Teagan Holt ${ }^{1}$ and Robert B. Laprairie ${ }^{1,2 *}$ \\ ${ }^{1}$ College of Pharmacy and Nutrition, University of Saskatchewan, Saskatoon, SK, Canada, ${ }^{2}$ Department of Pharmacology, \\ College of Medicine, Dalhousie University, Halifax, NS, Canada
}

\section{OPEN ACCESS}

Edited by:

Paula Morales,

Institute of Medical Chemistry,

Spanish National Research Council

(CSIC), Spain

Reviewed by:

Fabrizio Sanna,

University of Cagliari, Italy

Luigi Bellocchio,

INSERM U1215 Neurocentre

Magendie, France

*Correspondence:

Robert B. Laprairie

robert.laprairie@usask.ca

Specialty section:

This article was submitted to

Neuropharmacology,

a section of the journal

Frontiers in Neuroscience

Received: 06 October 2021 Accepted: 02 December 2021 Published: 21 December 2021

Citation:

Kim HJJ, Zagzoog A,

Smolyakova AM, Ezeaka UC, Benko MJ, Holt T and Laprairie RB

(2021) In vivo Evidence for Brain

Region-Specific Molecular Interactions Between Cannabinoid and Orexin Receptors.

Front. Neurosci. 15:790546. doi: 10.3389/fnins.2021.790546
The endocannabinoid and orexin neuromodulatory systems serve key roles in many of the same biological functions such as sleep, appetite, pain processing, and emotional behaviors related to reward. The type 1 cannabinoid receptor (CB1R) and both subtypes of the orexin receptor, orexin receptor type 1 (OX1R) and orexin receptor type 2 (OX2R) are not only expressed in the same brain regions modulating these functions, but physically interact as heterodimers in recombinant and neuronal cell cultures. In the current study, male and female C57BL/6 mice were co-treated with the cannabinoid receptor agonist CP55,940 and either the OX2R antagonist TCS-OX2-29 or the dual orexin receptor antagonist (DORA) TCS-1102. Mice were then evaluated for catalepsy, body temperature, thermal anti-nociception, and locomotion, after which their brains were collected for receptor colocalization analysis. Combined treatment with the DORA TCS-1102 and CP55,940 potentiated catalepsy more than CP55,940 alone, but this effect was not observed for changes in body temperature, nociception, locomotion, or via selective OX2R antagonism. Co-treatment with CP55,940 and TCS-1102 also led to increased CB1R-OX1R colocalization in the ventral striatum. This was not seen following co-treatment with TCS-OX2-29, nor in CB1R-OX2R colocalization. The magnitude of effects following co-treatment with CP55,940 and either the DORA or OX2R-selective antagonist was greater in males than females. These data show that CB1R-OX1R colocalization in the ventral striatum underlies cataleptic additivity between CP55,940 and the DORA TCS-1102. Moreover, cannabinoid-orexin receptor interactions are sexspecific with regards to brain region and functionality. Physical or molecular interactions between these two systems may provide valuable insight into drug-drug interactions between cannabinoid and orexin drugs for the treatment of insomnia, pain, and other disorders.

Keywords: cannabinoid, cannabinoid receptor, receptor antagonist, orexin receptor, heterodimerization, colocalization, tetrad analysis, ventral striatum 


\section{INTRODUCTION}

Endocannabinoid and orexin interdependence has been a topic of growing interest in the last two decades. Within the endocannabinoid system (ECS), lipid-based agonists, anandamide (AEA) and 2-arachidonoylglycerol (2-AG) primarily bind to 2 subtypes of the cannabinoid $G$ proteincoupled receptors (GPCR), cannabinoid receptor type 1 (CB1R) and cannabinoid receptor type 2 (CB2R). The orexin system shares many physical and functional similarities with the ECS (Berrendero et al., 2018). It consists of the neuropeptides orexin A (OXA) and orexin B (OXB), which activate GPCRs, orexin receptor type $1(\mathrm{OX} 1 \mathrm{R})$ and type $2(\mathrm{OX} 2 \mathrm{R})$. Cannabinoid and orexin receptors are found in many of the same brain regions underlying complex behaviors such as sleep, appetite, and reward processing. In mice and humans, cannabinoid receptor (CBR) activation leads to sedative effects such as catalepsy, hypothermia, analgesia, and anti-locomotion (Metna-Laurent et al., 2017; Zagzoog et al., 2020, 2021). Orexin receptor activation increases arousal, body temperature, and modulates anti-nociception at the spinal and supraspinal levels (Yamanaka et al., 2003; Monda et al., 2005; Chiou et al., 2010). Dual orexin receptor antagonists (DORA) are emerging as safe and effective treatments for insomnia (Herring et al., 2019), while phytocannabinoids such as cannabidiol and $\Delta^{9}$-tetrahydrocannabinol $\left(\Delta^{9}\right.$-THC), are used as off-label sleep aids as they affect the same sleep-wake neuropathways (Babson et al., 2017). Molecular and cellular interactions between these neuromodulatory systems have physiological implications in homeostasis, neurological and psychiatric disorders, as well as in drug-drug interactions between cannabinoid and orexin drugs.

Evidence for physical interactions between the endocannabinoid and orexin systems lies in the colocalization and potential heterodimerization of these two system's receptors (Jäntti et al., 2014; Berrendero et al., 2018). CB1R co-localizes with both OX1R and OX2R in the neocortex, hippocampus, thalamus, hypothalamus, amygdala, ventral tegmental area, periaqueductal gray, dorsal raphe nucleus, and deep cerebellar nuclei (Marcus et al., 2001; Mackie, 2005; Flores et al., 2014). Bioluminescence resonance energy transfer studies have found that OX1R and OX2R are capable of forming homo- and heterodimeric complexes with one another and with $\mathrm{CB} 1 \mathrm{R}$ (Jäntti et al., 2014). Moreover, fluorescence resonance energy transfer imaging demonstrates that CB1R-OX1R heterodimers reside in intracellular vesicles following CB1R agonist-mediated receptor internalization (Ellis et al., 2006; Ward et al., 2011). In recombinant cells co-expressing these receptor subtypes, OX1R activity not only induces 2-AG synthesis, but it also potentiates extracellular-signal-regulated kinase (ERK) activity of these recombinant cells (Jäntti et al., 2014). The reverse has been shown, as CB1R activation increases OXA's potency to activate ERK in cells where CB1R and OX1R are colocalized and potentially heterodimerized (Hilairet et al., 2003). In addition to recombinant cells, CB1R-OX1R complexes have also been observed in embryonic mouse hypothalamic neurons, supporting the workings of these heterodimers in vivo (Imperatore et al., 2016).
Although CB1R-OX1R heterodimers have not previously been directly observed in animals, rodent studies in which cannabinoid and orexin compounds are co-administered have described unique physiological and behavioral outcomes based on (1) the receptor subtype targeted, and (2) separate versus combined compound treatments. Activating CBRs while blocking orexin receptors causes sedation or sleep-like effects (Flores et al., 2016; Petrunich-Rutherford and Calik, 2021). In contrast, acutely activating both cannabinoid and orexin receptors increases appetite (Mechoulam and Fride, 2001; Merroun et al., 2015) and reward sensitivity (Plaza-Zabala et al., 2012; Flores et al., 2014; Yazdi et al., 2015). Thus, cannabinoid and orexin receptors may potentiate one another in brain regions modulating appetite and reward, while having antagonistic interactions in regions underlying arousal and sleep. Dual control of these biological functions is receptor-subtype specific. Physiological and behavioral regulation of body temperature, nociception processing, locomotion, appetite, and cognition are thought to be primarily CB1R-dependent based on the higher abundance of CB1R compared to CB2R (Zanettini et al., 2011). Between the orexin receptor subtypes, persistent $\mathrm{OX} 2 \mathrm{R}$ activity is believed to be more critical for maintaining arousal (Willie et al., 2003; Mieda et al., 2011) and caloric homeostasis (Funato et al., 2009). The combined observations of heterodimerization in vitro, existence in the same brain regions in vivo, and overlapping physiological effects of the ECS and orexin system support the hypothesis that co-manipulation of both systems will produce a fundamentally different outcome than targeting either system alone.

\section{MATERIALS AND METHODS}

\section{Compounds}

CP55,940 (Cat \# 90084) and TCS-1102 (Cat \# 18495) were purchased from Cayman Chemical Company (Ann Arbor, MI). TCS-OX2-29 was purchased from Abcam (Waltham, MA, Cat \# 141316). All compounds were stored at $-20^{\circ} \mathrm{C}$ until use. CP55,940 was first dissolved in 100\% methanol, then added to a vehicle solution consisting of: 1 part ethanol, 1 part Kolliphor EL (MilliporeSigma, Oakville), and 18 parts $1 \mathrm{M}$ phosphatebuffered saline (PBS) (Fisher, Waltham, MA). The concentration of stock solution used for CP55,940 varied based on animal weight and treatment dose. TCS-OX2-29 and TCS-1102 were first dissolved in a $10 \%$ DMSO solution in PBS, then added to a vehicle solution consisting of 1 part ethanol, 1 part Kolliphor EL, and 18 parts PBS. TCS-OX2-29 was prepared as a $5 \mathrm{mg} / \mathrm{mL}$ stock solution. TCS-1102 was prepared as a $1.5 \mathrm{mg} / \mathrm{mL}$ stock solution. All compounds were prepared at room temperature, after which they were stored at $4^{\circ} \mathrm{C}$ overnight before use the next morning.

\section{Animals and Tetrad Testing}

Adult male and female C57BL/6 mice aged 6-12 weeks (mean weight of males: $22 \pm 0.3 \mathrm{~g}$; mean weight of females: $20 \pm 0.3 \mathrm{~g}$ ) were purchased from Charles River Labs (Senneville, QC). Mice were group housed (males: 3 per cage; females: 5 per cage) with ad libitum access to food, water, and environmental enrichment. All mice were maintained on a $12 \mathrm{~h}$ light:dark cycle 
(07:00-19:00/19:00-07:00). Mice were randomly designated to receive 2 intraperitoneal (i.p.) injections ( 1 on each side) of the following treatment combinations: vehicle and CP55,940 at 5 doses $(0.1,0.3,1$, and $3 \mathrm{mg} / \mathrm{kg})$, vehicle and TCS-OX2-29 at 4 doses $(1,10,18$, and $30 \mathrm{mg} / \mathrm{kg})$, vehicle and TCS-1102 at 4 doses $(0.1,0.3,1$, and $10 \mathrm{mg} / \mathrm{kg}), 1 \mathrm{mg} / \mathrm{kg} \mathrm{CP} 55,940$ and TCS-OX2$29(1,10,18$, and $30 \mathrm{mg} / \mathrm{kg})$ at 4 doses, or $1 \mathrm{mg} / \mathrm{kg}$ CP55,940 and TCS-1102 $(0.1,0.3,1$, and $10 \mathrm{mg} / \mathrm{kg})$ at 4 doses, totaling 22 treatment groups ( $n=6$ per group). CP55,940 doses were based on previously published studies from our group in the same battery of in vivo assays (Zagzoog et al., 2020, 2021). TCS-OX229 doses were chosen to build on the work of Flores et al. (2016), who had tested $10 \mathrm{mg} / \mathrm{kg}$ of TCS-OX2-29 in mice. Because TCS1102 has not previously been assessed in the tetrad, doses of TCS-1102 were also chosen based on Flores et al. (2016). For combination treatments, $1 \mathrm{mg} / \mathrm{kg}$ CP55,940 was chosen as an approximation of the $\mathrm{ED}_{80}$ for this compound. These doses were piloted by our group for safety and effect prior to data collection for the current study. These 22 treatment groups were tested in both males and females, totaling 264 mice used throughout the study. All protocols were in accordance with the guidelines detailed by the Canadian Council on Animal Care (CCAC; Ottawa ON: Vol. 1, second Ed., 1993; Vol. 2, 1984) and approved by the Animal Research Ethics Board and the Scientific Merit Review Committee for Animal Behavior at the University of Saskatchewan. In keeping with the Animal Research: Reporting of In Vivo Experiments (ARRIVE) guidelines, power analyses were conducted to determine the minimum number of mice required for the study, and mice were purchased, rather than bred, to limit animal waste (Kilkenny et al., 2010).

Tetrad testing commenced 10 min after i.p. injections with the ring holding assay to measure catalepsy. For this assay, mice were placed on the ring apparatus such that their forepaws clasped the $5 \mathrm{~mm}$ ring positioned $5 \mathrm{~cm}$ above the surface of the testing platform. The length of time that the ring was clasped was recorded (s). The trial was completed when the mouse turned its head or body, made 3 consecutive escape attempts, or at $60 \mathrm{~s}$ of immobility [i.e., maximum possible effect $(\mathrm{MPE})=60 \mathrm{~s}]$. Internal body temperature was recorded $15 \mathrm{~min}$ after the injections via a rectal thermometer $\left({ }^{\circ} \mathrm{C}\right)$. Thermal antinociception was assessed by the tail flick latency test $20 \mathrm{~min}$ following the injections. Mice were restrained with their tails placed $\sim 1 \mathrm{~cm}$ into $52 \pm 2^{\circ} \mathrm{C}$ water. The time until the tail was removed from the water was recorded as the tail flick latency (s). Tails were removed after $20 \mathrm{~s}$ if they had not been removed already (i.e., MPE $=20$ s). Locomotion was measured in the open field test $25 \mathrm{~min}$ following the injections. Mice were placed in the $55 \mathrm{~cm} \times 55 \mathrm{~cm}$ square-shaped open field for $10 \mathrm{~min}$, during which they were free to roam. Distance traveled $(\mathrm{m})$ and average velocity $(\mathrm{cm} / \mathrm{s})$ were measured with EthoVision XT (Noldus Information Technology Inc., Leesburg, VA). Distance and velocity scores were then normalized and expressed as a percentage of vehicle means (\%Vehicle). For statistical processing, tetrad scores were averaged between mice in the same drug treatment group (Zagzoog et al., 2020, 2021).

\section{Tissue Perfusion and Immunohistochemistry}

A separate set of mice were euthanized, and their brains were collected $30 \mathrm{~min}$ after i.p. injections. This tissue collection time was based on the tetrad timeline, as treated mice finished the tetrad test 30-35 min post-injection. Mice were placed in a rodent vapor chamber, which delivered a mixture of oxygen and isoflurane for approximately $2 \mathrm{~min}$ before the animal was fully anesthetized. Mice were then transcardially perfused with $5 \mathrm{~mL}$ of ice cold $0.9 \%$ saline solution, followed by $5 \mathrm{~mL}$ of ice cold $4 \%$ paraformaldehyde solution. Brains were rapidly dissected from the skull then submerged in $4 \%$ paraformaldehyde solution on ice. The perfused mouse brains were then stored at $4^{\circ} \mathrm{C}$ for 1 day before being submerged in 30\% sucrose solution and stored at $4^{\circ} \mathrm{C}$ for another 1-1.5 days. Once the brains sunk to the bottom of the sucrose solution, the sucrose solution was drained, and the brains underwent flash-freezing using liquid nitrogen. Frozen brains were stored at $-80^{\circ} \mathrm{C}$ prior to slicing. For slicing, frozen brains were embedded in TissuePlus $^{\mathrm{TM}}$. C.T. Compound (Fisher, Waltham, MA), then sliced at a thickness of $20 \mu \mathrm{m}$ using a cryostat held at $-20^{\circ} \mathrm{C}$. Slices were mounted on Superfrost ${ }^{\mathrm{TM}}$ Plus microscope slides (Fisher, Waltham, MA) then stored at $-20^{\circ} \mathrm{C}$ until they were used for immunohistochemistry.

The immunohistochemistry procedure consisted of the following steps: (1) blocking endogenous peroxidase by incubating with $0.3 \% \mathrm{H}_{2} \mathrm{O}_{2}$ at room temperature for $10 \mathrm{~min}$, (2) rinsing in $1 \mathrm{M} \mathrm{PBS} 3$ times for 5 min each time, (3) blocking non-specific binding at room temperature by incubating in $10 \%$ fetal bovine serum at room temperature for $2 \mathrm{~h}$, (4) incubating with primary antibodies at $4^{\circ} \mathrm{C}$ for $24 \mathrm{~h}$, (5) rinsing in $1 \mathrm{M}$ PBS 3 times for 5 min each, (6) incubating in secondary antibodies at room temperature for $1 \mathrm{~h}$, at which point all steps proceeded in the dark due to the secondary antibodies' light sensitivity, (7) rinsing in $1 \mathrm{M}$ PBS 3 times for $5 \mathrm{~min}$ each, and (8) mounting the immuno-stained slices using ProLong ${ }^{\text {TM }}$ Gold Antifade Mountant with DAPI (ThermoFisher Scientific, Waltham, Massachusetts). All immune-stained slices were stored at $4^{\circ} \mathrm{C}$ before imaging. The following primary antibodies were used: cannabinoid receptor CB1R monoclonal antibody (mouse, Synaptic Systems, Göttingen, Germany, Lot 1-3, Cat \# 258011) diluted at 1:500, orexin receptor 1 polyclonal antibody (rabbit, Enzo Life Sciences, Farmingdale, NY, Lot 10122020, Cat \# BML-KI508) diluted at 1:50, orexin receptor 2 polyclonal antibody (rabbit, Enzo Life Sciences, Farmingdale, NY, Lot 10122020, Cat \# BML-KI507) diluted at 1:200. The following secondary antibodies were used: Goat Anti-Mouse IgG H\&L (Alexa Fluor ${ }^{\circledR}$ 594) (Invitrogen, Eugene, Oregon, Lot 2179228, Cat \# A11005) diluted at 1:500 was used for the mouse anti-CB1R primary antibody, while Goat Anti-Rabbit IgG H\&L (Alexa Fluor ${ }^{\circledR} 488$ ) (Invitrogen, Eugene, Oregon, Lot 2179202, Cat \# A11008) diluted at 1:500 was used for the rabbit-anti-OX1R and -OX2R antibodies. Each brain region was triple-labeled with (1) DAPI-CB1R-OX1R or (2) DAPI-CB1R-OX2R. 


\section{Confocal Microscopy and Colocalization Analysis}

A Zeiss LSM700 confocal microscope (Carl Zeiss, Oberkochen, Germany) equipped with Zeiss ZEN Black (version 2.3 SP1) software (Carl Zeiss, Oberkochen, Germany) was used to obtain fluorescent 3D images of the immuno-stained brain slices. 10-12 Z-stacks encompassing an average tissue depth of $15 \mu \mathrm{m}$ were collected at $63 \mathrm{X}$ oil immersion from each ventral striatum and primary motor cortex. ImageJ (version 2.1.0) (NIH, Bethesda, MD, United States) was used to merge the Z-stacks to form 3D images for analysis. Within each image, DAPIimmunolabeled cells were randomly chosen for colocalization analysis on ImageJ and its Fiji package (NIH, Bethesda, MD, United States). Pearson's correlation coefficients were calculated for (1) CB1R-OX1R, and (2) CB1R-OX2R (Zinchuk and Zinchuk, 2008). For statistical processing, CB1R-OX1R and CB1R-OX2R colocalization coefficients were averaged between $n=6$ cells in the same sex and drug treatment group.

\section{Statistical Analysis}

Tetrad data are presented as mean \pm SEM where " $n$ " represents the number of animals per treatment group. Data from the ring holding assay and tail flick assay are reported as percent maximum possible effect (\%MPE) for catalepsy and \%MPE for anti-nociception, respectively. Results from the open field test are stated as a percentage of vehicle scores (\%Vehicle). Doseresponse curves were fit using a three parameter non-linear regression to yield the $E D_{50}$ and $E_{\text {max }}$ values (GraphPad, Prism, v. 9.0.1, San Diego, CA). For data without a clear dose-response (i.e., non-converged/“n.c."), $E_{\text {max }}$ was reported as the maximum response observed. All $E_{\text {max }}$ data are reported as mean \pm SEM. $E D_{50}$ data are reported as the mean with $95 \%$ confidence interval (CI). Isobolographic analyses for body temperature were conducted using $E D_{50}$ data with $95 \%$ CI only because $E D_{50}$ could not be estimated in other data sets. Homogeneity of variance was confirmed using Bartlett's test. Statistical analyses for tetrad data were conducted by two-way analysis of variance (ANOVA) to account for both sex and drug treatment. Immunohistochemistry colocalization data are presented as a mean \pm SEM where " $n$ " represents individual cells counted within the brain region of a single mouse. Colocalization means are denoted as Pearson's correlation coefficients. Statistical analyses for the colocalization data were conducted by two-way ANOVA to account for both sex and drug treatment. Post hoc analyses were performed using Tukey's (two-way ANOVA) test. Significance was set as $p<0.05$.

\section{RESULTS}

\section{Catalepsy}

Male and female C57BL/6 mice were treated with CP55,940 (0.1-10 mg/kg), TCS-OX2-29 (1-30 mg/kg), TCS-1102 (0.1$10 \mathrm{mg} / \mathrm{kg})$, and co-treatments of $1 \mathrm{mg} / \mathrm{kg} \mathrm{CP55,940}$ and either TCS-OX2-29 (1-30 mg/kg) or TCS-1102 (0.1-10 mg/kg). Treatment with CP55,940 alone or $1 \mathrm{mg} / \mathrm{kg}$ CP55,940 + TCS1102 produced a dose-dependent increase in catalepsy in both sexes (Figures 1A,B). Co-treatment with $1 \mathrm{mg} / \mathrm{kg}$

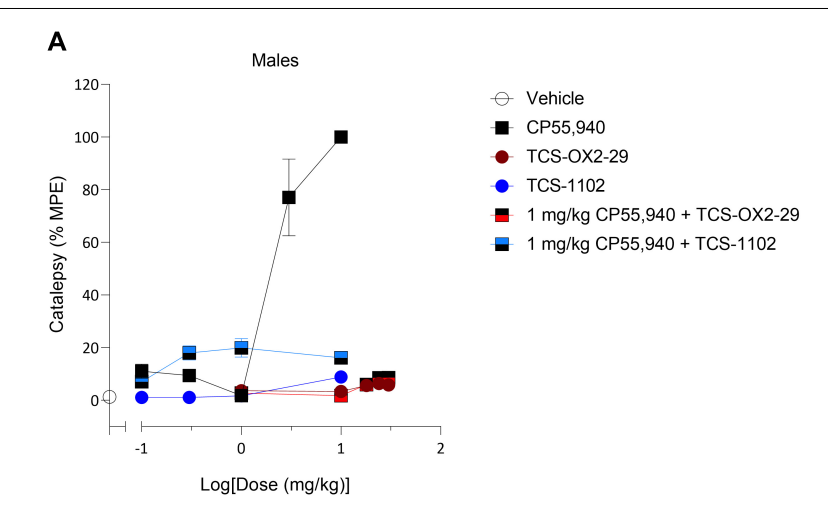

B

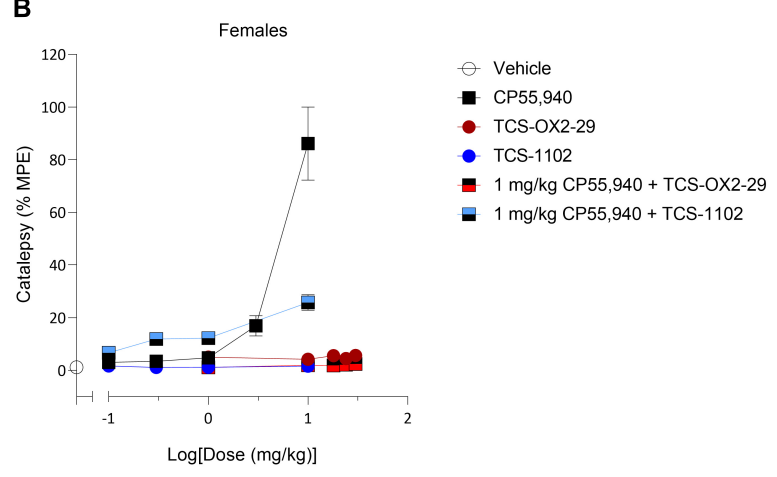

c
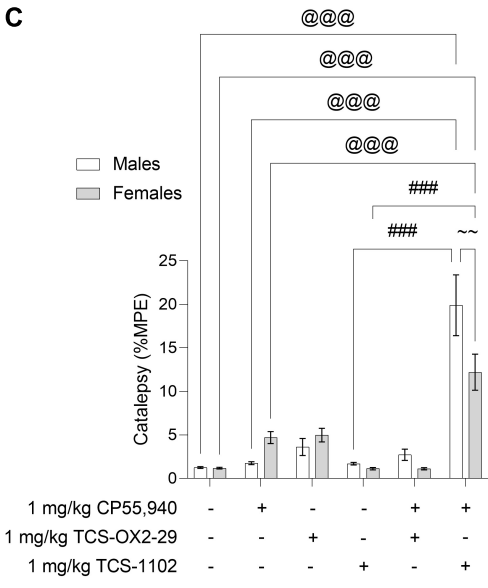

FIGURE 1 | Acute catalepsy effects following cannabinoid and orexin drug treatments. Male (A) and female (B) C57BL/6 mice aged 6-12 weeks were i.p. administered one of the following dose ranges: CP55,940 (0.1-10 mg/kg), TCS-OX2-29 (1-30 mg/kg), TCS-1102 (0.1-10 mg/kg), $1 \mathrm{mg} / \mathrm{kg}$ CP55,940 + TCS-OX2-29 (1-30 mg/kg), or 1 mg/kg CP55,940 + TCS-1102 $(0.1-10 \mathrm{mg} / \mathrm{kg}) .10 \mathrm{~min}$ post-injections, mice were assessed for catalepsy in the ring holding assay. (C) Cataleptic responses were compared within (sex) and between (drugs) the following experimental groups: $1 \mathrm{mg} / \mathrm{kg}$ CP55,940, $1 \mathrm{mg} / \mathrm{kg}$ TCS-OX2-29, $1 \mathrm{mg} / \mathrm{kg}$ TCS-1102, $1 \mathrm{mg} / \mathrm{kg}$ CP55,940 + $1 \mathrm{mg} / \mathrm{kg}$ TCS-OX2-29, or $1 \mathrm{mg} / \mathrm{kg}$ CP55,940 + $1 \mathrm{mg} / \mathrm{kg}$ TCS-1102. All catalepsy data are expressed as \%MPE (MPE = $60 \mathrm{~s}$ ), and as means \pm SEM. $n=6$ for all treatment groups. Significance was calculated using a two-way ANOVA 
FIGURE 1 | followed by Tukey's post hoc analyses. @@@ $p<0.001$ compared to Vehicle within sexes. \#\#\#p < 0.001 compared between $1 \mathrm{mg} / \mathrm{kg}$ TCS-1102 and $1 \mathrm{mg} / \mathrm{kg}$ CP55,940 + $1 \mathrm{mg} / \mathrm{kg}$ TCS-1102. $\sim p<0.01$ compared between sexes, within treatment groups.

CP55,940 + TCS-1102 was less potent in producing catalepsy compared to CP55,940 alone in both sexes (Table 1). There were no sex differences within drug treatments. Potency differences could not be calculated between or within these other experimental groups because no clear dose-response was observed for all treatments (Table 1). Co-treatments of $1 \mathrm{mg} / \mathrm{kg}$ CP55,940 + TCS-OX2-29 or $1 \mathrm{mg} / \mathrm{kg}$ CP55,940 + TCS- 1102 were less efficacious than $1 \mathrm{mg} / \mathrm{kg}$ CP55,940 alone $(p<0.001)$ (Table 1). Looking at the TCS-1102 treatments in females, co-treatment with $1 \mathrm{mg} / \mathrm{kg}$ CP55,940 + TCS-1102 was more efficacious than TCS-1102 alone ( $p=0.0159)$ (Table 1). There were no efficacy differences between any of the other drug treatments, nor between sexes.

Co-treatment with $1 \mathrm{mg} / \mathrm{kg} \mathrm{CP} 55,940+1 \mathrm{mg} / \mathrm{kg}$ TCS1102 produced a larger cataleptic response compared to either $1 \mathrm{mg} / \mathrm{kg}$ CP55,940 alone or $1 \mathrm{mg} / \mathrm{kg}$ TCS-1102 alone in both sexes $(p<0.001)$ (Figure 1C). Thus, the combination of $1 \mathrm{mg} / \mathrm{kg}$ of CP55,940 $+1 \mathrm{mg} / \mathrm{kg}$ of TCS-1102 potentiated catalepsy, suggesting additivity between these two drugs. Considering that only co-treatment with the DORA TCS-1102

TABLE $1 \mid E D_{50}$ and $E_{\max }$ values reflecting catalepsy responses to cannabinoid and orexin drug treatments.

\begin{tabular}{lcc}
\hline \multirow{2}{*}{ Treatment } & $E D_{\mathbf{5 0}}(\mathbf{m g} / \mathbf{k g})(\mathbf{9 5} \% \mathbf{C l})$ & $E_{\max }(\% \mathrm{MPE}) \pm \mathrm{SEM}$ \\
\cline { 2 - 3 } & \multicolumn{2}{c}{ Males } \\
\hline CP55,940 & $2.4(1.3-4.3)$ & 100 \\
TCS-OX2-29 & n.c. & $5.8 \pm 0.83$ \\
TCS-1102 & n.c. & $8.8 \pm 1.2$ \\
$1 \mathrm{mg} / \mathrm{kg}$ & n.c. & $8.6 \pm 0.52^{\star}$ \\
CP55,940 + TCS-OX2-29 & & $19 \pm 1.5^{\star}$ \\
$1 \mathrm{mg} / \mathrm{kg}$ & 41 (19-87) & \\
CP55,940 + TCS-1102 & &
\end{tabular}

\begin{tabular}{lcc}
\hline & \multicolumn{2}{c}{ Females } \\
\cline { 2 - 3 } CP55,940 & $5.7(3.6-9.3)$ & $86 \pm 14$ \\
TCS-0X2-29 & n.c. & $5.7 \pm 1.2$ \\
TCS-1102 & n.c. & $1.6 \pm 0.29$ \\
$1 \mathrm{mg} / \mathrm{kg}$ & n.c. & $2.8 \pm 1.5^{\star}$ \\
CP55,940 + TCS-OX2-29 & & \\
$1 \mathrm{mg} / \mathrm{kg}$ & $26(18-38)^{\star}$ & $26 \pm 3.0^{\star} \#$ \\
CP55,940 + TCS-1102 & & \\
\hline
\end{tabular}

Data were fit to a three parameter non-linear regression with a system minimum and maximum constrained to 0 and 100, respectively (GraphPad, Prism, v. 8.0). n.c., not converged.

For data without a clear dose-response (i.e., "n.c."), $E_{\max }$ is reported as the maximum response observed.

Data are expressed as $\mathrm{mg} / \mathrm{kg}$ with $95 \% \mathrm{Cl}$ or \%MPE \pm SEM.

${ }^{*} p<0.05$ compared to CP55,940 within sexes, and \#p < 0.05 compared between $1 \mathrm{mg} / \mathrm{kg}$ TCS-1102 and $1 \mathrm{mg} / \mathrm{kg}$ CP55,940 + $1 \mathrm{mg} / \mathrm{kg}$ TCS-1102, as determined by non-overlapping 95\% Cl or two-way ANOVA followed by Tukey's post hoc test. Corresponding graph is presented in Figure 1. potentiated catalepsy, these results imply that compared to OX2R antagonism, OX1R antagonism is more critical in potentiating CP55,940-induced catalepsy. In terms of sex differences, males had a larger cataleptic response to the co-treatment with CP55,940 + TCS-1102 compared to females, demonstrating that males are more sensitive to the cataleptic effects of coadministered cannabinoid and DORA $(p=0.0032)$ (Figure 1C).

\section{Body Temperature}

With the exception of TCS-1102 treatment in males, all compounds tested produced a dose-dependent decrease in body temperature (Figures 2A,B). Co-treatment with $1 \mathrm{mg} / \mathrm{kg}$ CP55,940 + TCS-OX2-29 was a less potent mediator of hypothermia than CP55,940 alone in both sexes (Table 2). Co-treatment with $1 \mathrm{mg} / \mathrm{kg}$ CP55,940 + TCS-OX2-29 was more efficacious in producing hypothermia than TCS-OX2-29 alone in both sexes $(p<0.001)$. Co-treatment with $1 \mathrm{mg} / \mathrm{kg}$ CP55,940 + TCS-1102 was also more efficacious in producing hypothermia compared to TCS-1102 alone in males $(p<0.001)$ and females $(p=0.0049)$ (Table 2). There were no potency or efficacy differences between any of the other drug treatments, nor between sexes.

Co-treatment with $1 \mathrm{mg} / \mathrm{kg}$ CP55,940 + $1 \mathrm{mg} / \mathrm{kg}$ TCS-1102 produced more hypothermia than $1 \mathrm{mg} / \mathrm{kg}$ TCS-1102 alone in both males $(p<0.001)$ and females $(p=0.0049)$ (Figure 2C). Co-treatment with $1 \mathrm{mg} / \mathrm{kg}$ CP55,940 $+1 \mathrm{mg} / \mathrm{kg}$ TCS-OX2-29 produced a greater decrease in body temperature than $1 \mathrm{mg} / \mathrm{kg}$ TCS-OX2-29 alone in both sexes $(p<0.001)$ (Figure 2C). Because these co-treatment effects are not greater than that of CP55,940 alone, hypothermia was likely CP55,940-driven. There were no sex differences in temperature between any of the other $1 \mathrm{mg} / \mathrm{kg}$ treatment groups. CP55,940-dependent hypothermia in mice appears to be CBR-dependent and not co-regulated by either OX1R or OX2R, nor sex-dependent.

Isobolograms comparing compound $E D_{50}$ values from Table 2 were constructed for body temperature data (Figure 3). Based on these isobolograms, co-treatments with CP55,940 + TCS-OX229 or CP55,940 + TCS-1102 were mapped to the non-significant antagonistic range in both sexes. This is in accordance with the conclusion drawn from Figure 2.

\section{Anti-nociception}

Dose-response relationships were observed for all groups excluding TCS-OX2-29 in females (Figures 4A,B). For experimental groups without clear dose-response plateaus, $E D_{50}$ was estimated to be greater than the maximum dose evaluated (Table 3). Based on this, the co-treatment with $1 \mathrm{mg} / \mathrm{kg}$ CP55,940 + TCS-1102 was more potent than $1 \mathrm{mg} / \mathrm{kg}$ CP55,940 alone in producing anti-nociception in males (Table 3). The co-treatment with $1 \mathrm{mg} / \mathrm{kg}$ CP55,940 + TCS-1102 was more than TCS-1102 alone in females (Table 3). The co-treatment with $1 \mathrm{mg} / \mathrm{kg}$ CP55,940 + TCS-OX2-29 was more potent compared to TCS-OX2-29 alone, but less potent compared to CP55,940 alone in females (Table 3). Lastly, the co-treatments with $1 \mathrm{mg} / \mathrm{kg}$ CP55,940 + TCS-OX2-29, and $1 \mathrm{mg} / \mathrm{kg}$ CP55,940 + TCS/1102, were more efficacious than TCS-OX2-29 alone $(p<0.001)$, and TCS-1102 alone (males: $p<0.001$, females: $p=0.093$ ), 


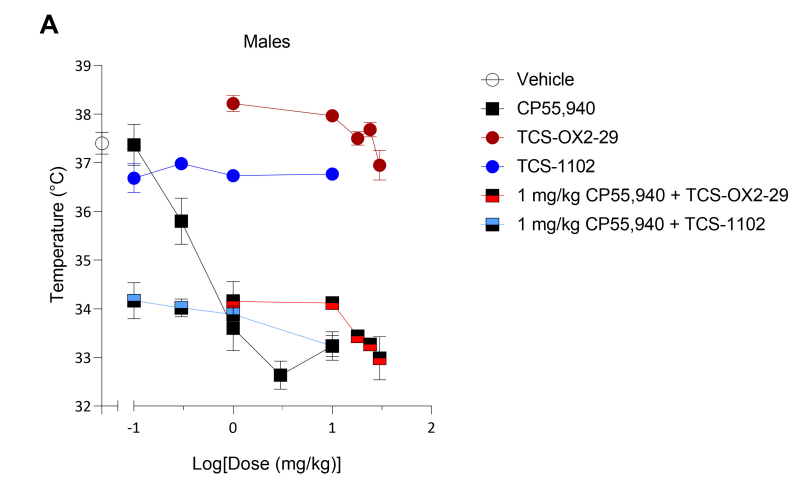

B

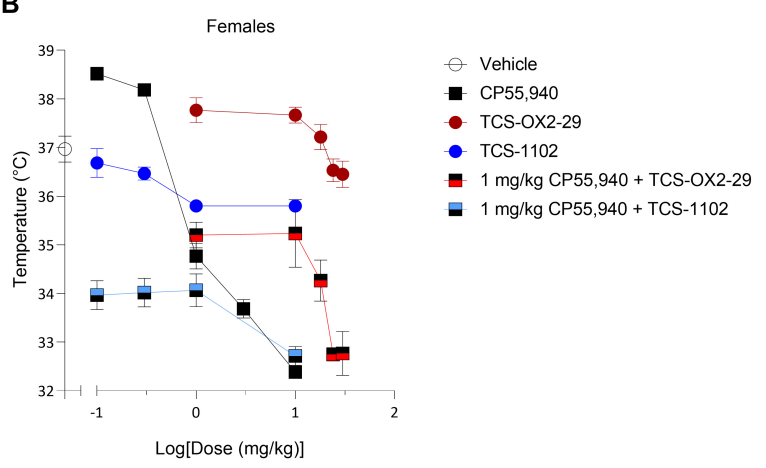

C

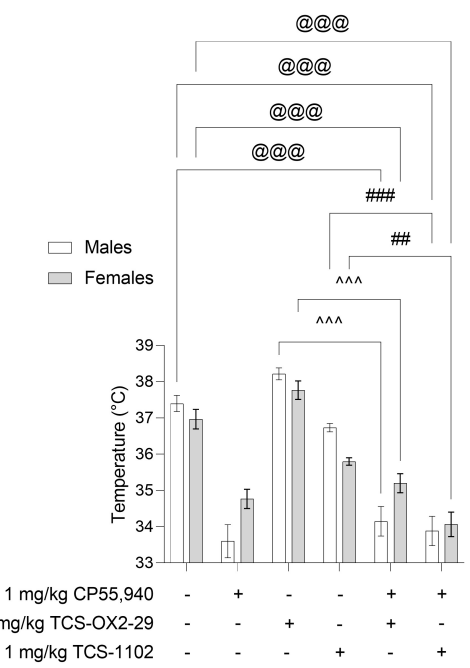

FIGURE 2 | Acute body temperature effects from cannabinoid and orexin drug treatments. Male (A) and female (B) C57BL/6 mice aged 6-12 weeks were i.p. administered one of the following dose ranges: CP55,940 (0.1-10 mg/kg), TCS-OX2-29 (1-30 mg/kg), TCS-1102 (0.1-10 mg/kg), 1 mg/kg CP55,940 + TCS-OX2-29 (1-30 mg/kg), or 1 mg/kg CP55,940 + TCS-1102 $(0.1-10 \mathrm{mg} / \mathrm{kg}) .15 \mathrm{~min}$ post-injections, a rectal thermometer was used to measure internal body temperature. (C) Temperature responses were compared within (sex) and between (drugs) the following experimental groups: 1 mg/kg CP55,940, 1 mg/kg TCS-OX2-29, 1 mg/kg TCS-1102,

(Continued)
FIGURE 2 | 1 mg/kg CP55,940 + 1 mg/kg TCS-OX2-29, or 1 mg/kg CP55,940 + $1 \mathrm{mg} / \mathrm{kg}$ TCS-1102. All catalepsy data are expressed as ${ }^{\circ} \mathrm{C}$, and as means \pm SEM. $n=6$ for all treatment groups. Significance was calculated using a two-way ANOVA followed by Tukey's post hoc analyses. @@@p $<0.001$ compared to Vehicle within sexes. ${ }^{m} p<0.001$ compared between $1 \mathrm{mg} / \mathrm{kg}$ TCS-OX2-29 and $1 \mathrm{mg} / \mathrm{kg}$ CP55,940 + $1 \mathrm{mg} / \mathrm{kg}$ TCS-OX2-29. \#\#/\#\#\#p < 0.01/0.001 compared between $1 \mathrm{mg} / \mathrm{kg}$ TCS-1102 and $1 \mathrm{mg} / \mathrm{kg}$ CP55,940 + $1 \mathrm{mg} / \mathrm{kg}$ TCS-1102.

respectively (Table 3 ). No potency or efficacy differences were detected between any other groups, nor between sexes.

Co-treatment with $1 \mathrm{mg} / \mathrm{kg}$ CP55,940 $+1 \mathrm{mg} / \mathrm{kg}$ TCSOX2-29 was associated with a greater anti-nociceptive response than $1 \mathrm{mg} / \mathrm{kg}$ TCS-OX2-29 alone in males $(p<0.001)$ (Figure 4C). Moreover, in males, co-treatment with $1 \mathrm{mg} / \mathrm{kg}$ CP55,940 $+1 \mathrm{mg} / \mathrm{kg}$ TCS-1102 produced a greater antinociceptive response than $1 \mathrm{mg} / \mathrm{kg}$ TCS-1102 alone $(p<0.001)$ (Figure 4C). There were no differences between compound treatments in females (Figure 4C). Given that neither of the cotreatments in males were more anti-nociceptive than CP55,940 alone, it was concluded that the anti-nociceptive effects of the cotreatments are CP55,940-driven (Figure 4C). With respect to sex differences, CP55,940 alone ( $p=0.0293)$ and both co-treatments of CP55,940 + TCS-OX2-29 $(p<0.001)$, and CP55,940 + TCS$1102(p<0.001)$, had higher analgesic effects in males compared

TABLE $2 \mid E D_{50}$ and $E_{\max }$ values reflecting body temperature responses to cannabinoid and orexin drug treatments.

\begin{tabular}{|c|c|c|}
\hline \multirow[t]{2}{*}{ Treatment } & $E D_{50}(\mathrm{mg} / \mathrm{kg})(95 \% \mathrm{Cl})$ & $E_{\max }\left({ }^{\circ} \mathrm{C}\right) \pm \mathrm{SEM}$ \\
\hline & \multicolumn{2}{|c|}{ Males } \\
\hline CP55,940 & $8.8(4.5-17)$ & $32 \pm 0.36$ \\
\hline TCS-OX2-29 & $>30$ & $37 \pm 0.36$ \\
\hline TCS-1102 & n.c. & $37 \pm 0.090$ \\
\hline $\begin{array}{l}1 \mathrm{mg} / \mathrm{kg} \\
\text { CP55,940 + TCS-OX2-29 }\end{array}$ & $>30$ & $33 \pm 0.45^{\wedge}$ \\
\hline \multirow{3}{*}{$\begin{array}{l}1 \mathrm{mg} / \mathrm{kg} \\
\text { CP55,940 + TCS-1102 }\end{array}$} & $12(5-31)$ & $33 \pm 0.87 \#$ \\
\hline & & \\
\hline & \multicolumn{2}{|c|}{ Females } \\
\hline CP55,940 & $8.6(4.2-17)$ & $32 \pm 0.31$ \\
\hline TCS-OX2-29 & $>30$ & $36 \pm 0.27$ \\
\hline TCS-1102 & $10(4.0-26)$ & $36 \pm 0.20$ \\
\hline $\begin{array}{l}1 \mathrm{mg} / \mathrm{kg} \\
\text { CP55,940 + TCS-OX2-29 }\end{array}$ & $>30$ & $33 \pm 0.45^{\wedge}$ \\
\hline $\begin{array}{l}1 \mathrm{mg} / \mathrm{kg} \\
\text { CP55,940 + TCS-1102 }\end{array}$ & $13(5.1-32)$ & $33 \pm 0.20 \#$ \\
\hline
\end{tabular}

Data were fit to a three parameter non-linear regression with a system minimum and maximum constrained to 0 and 100, respectively (GraphPad, Prism, v. 8.0). n.c., not converged.

For data without a clear dose-response (i.e., "n.c."), $E_{\max }$ is reported as the maximum response observed.

Data are expressed as $\mathrm{mg} / \mathrm{kg}$ with $95 \% \mathrm{Cl}$ or ${ }^{\circ} \mathrm{C} \pm$ SEM.

$\hat{p}<0.05$ compared between $1 \mathrm{mg} / \mathrm{kg}$ TCS-OX2-29 and $1 \mathrm{mg} / \mathrm{kg}$ CP55,940 + $1 \mathrm{mg} / \mathrm{kg}$ TCS-OX2-29, and \#p < 0.05 compared between $1 \mathrm{mg} / \mathrm{kg}$ TCS-1102 and $1 \mathrm{mg} / \mathrm{kg}$ CP55,940 + $1 \mathrm{mg} / \mathrm{kg}$ TCS-1102, as determined by nonoverlapping 95\% Cl or two-way ANOVA followed by Tukey's post hoc test. Corresponding graph is presented in Figure 2. 

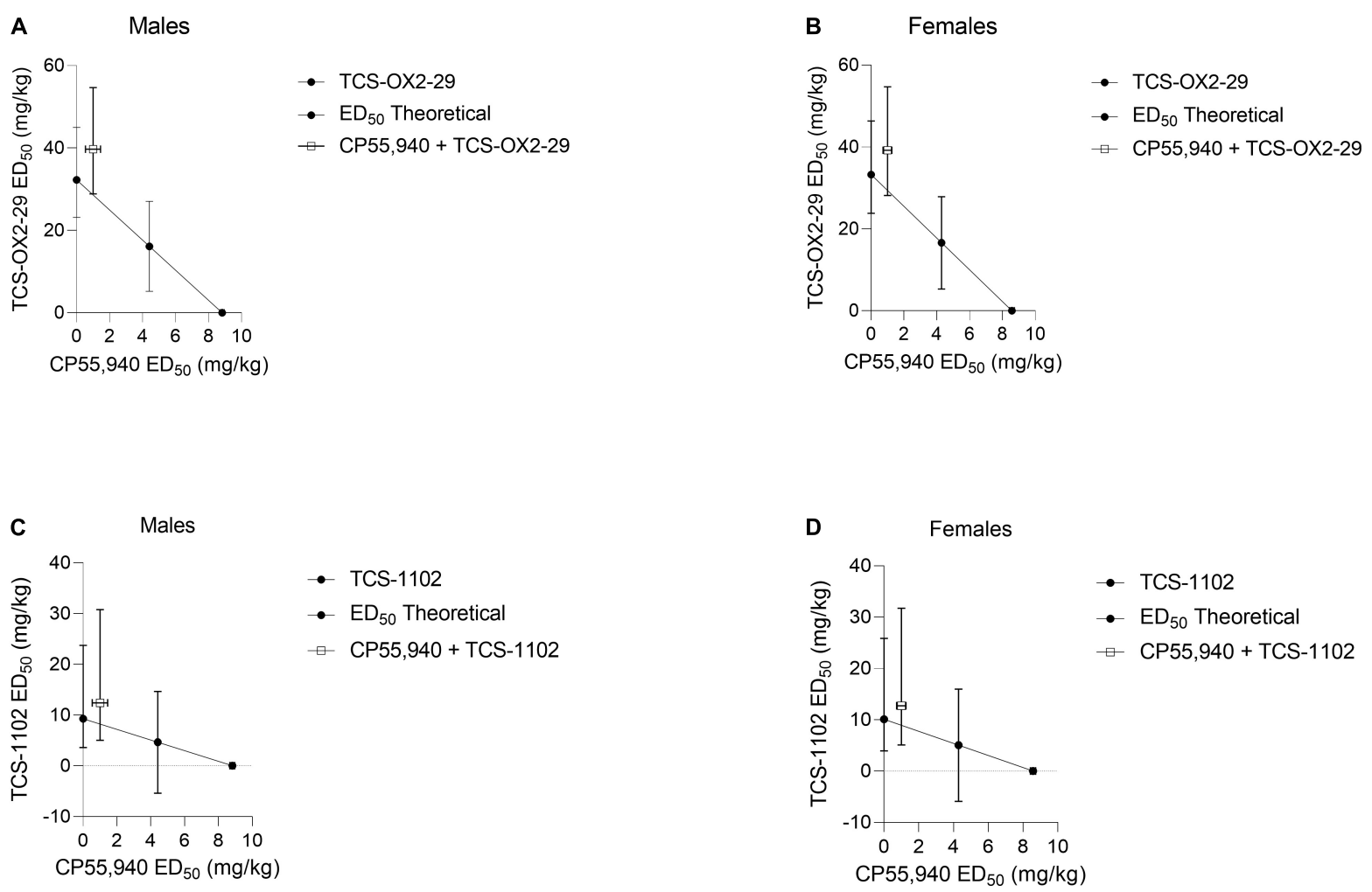

FIGURE 3 | Isobolograms determining drug-drug interactions between cannabinoid and orexin drugs with regards to body temperature. CP55,940 co-treatments with both TCS-OX2-29 (A,B) and TCS-1102 (C,D) caused non-significant antagonistic body temperature effects in both male (A,C) and female (B,D) C57BL/6 mice. Data were fit to a three parameter non-linear regression with a system minimum and a system maximum constrained to 0 and 100 , respectively. Data are expressed as $\mathrm{mg} / \mathrm{kg}$ with $95 \% \mathrm{Cl}$.

to females (Figure 4C). Sex differences in nociception were not detected in the orexin receptor antagonist treatments. Therefore, CP55,940-dependent anti-nociception in mice is likely CB1Rdependent and not co-regulated by either OX1R or OX2R, nor sex-dependent.

\section{Locomotion}

CP55,940, TCS-OX2-29, and TCS-1102 produced dosedependent decreases in locomotion and velocity in both sexes; however, $E D_{50}$ values could not be estimated for $1 \mathrm{mg} / \mathrm{kg}$ CP55,940 + TCS-1102 as no plateau was observed (Figure 5 and Table 4). No differences were seen between treatment groups, nor between sexes with regards to the potency in decreasing distance and velocity (Table 4). In both sexes, CP55,940 was more efficacious than TCS-OX2-29 alone and TCS-1102 alone in decreasing distance and velocity (distance in males: $p=0.0399$; all other groups: $p<0.0001$ ) (Table 4). Also in both sexes, co-treatment with $1 \mathrm{mg} / \mathrm{kg}$ CP55,940 + TCS-OX2-29 was more efficacious than TCS-OX2-29 alone in decreasing both distance and velocity in both sexes (velocity in females: $p=0.0106$; all other groups: $p<0.0001$ ) (Table 4). In females, co-treatment with $1 \mathrm{mg} / \mathrm{kg}$ CP55,940 + TCS-1102 was more efficacious than TCS-110 alone in decreasing distance $(p=0.0005)$ (Table 4). Co-treatment with $1 \mathrm{mg} / \mathrm{kg}$ CP55,940 + TCS-1102 was also more efficacious than TCS-1102 alone in decreasing velocity in both sexes $(p<0.0001)$ (Table 4). No other treatment or sex differences were observed in the distance and velocity $E_{\text {max }}$ values.

Co-treatment with $1 \mathrm{mg} / \mathrm{kg}$ CP55,940 + $1 \mathrm{mg} / \mathrm{kg}$ TCSOX2-29 had greater anti-locomotive effects (decreased distance and velocity) compared to TCS-OX2-29 alone in both sexes $(p<0.001)$ (Figures 5E,F). Similarly, co-treatment with $1 \mathrm{mg} / \mathrm{kg}$ CP55,940 + $1 \mathrm{mg} / \mathrm{kg}$ TCS-1102 had greater anti-locomotive effects (decreased distance and velocity) compared to TCS-1102 alone in both sexes $(p<0.001)$ (Figures 5E,F). Locomotion in the open field test is visualized in representative heat maps (Figures 5G,H). Because no co-treatment exacerbated the anti-locomotive effects of CP55,940 alone, the anti-locomotive effects are likely CP55,940-driven. Lastly, there were no sex differences within any of the drug treatments. Therefore, CP55,940-dependent locomotor effects in mice appear to be CB1R-dependent and not co-regulated by either OX1R or OX2R, nor sex-dependent.

\section{CB1R and OX1R/OX2R Colocalization}

Thirty min post-injection, brain tissue was collected from the following drug treatment groups: $1 \mathrm{mg} / \mathrm{kg}$ CP55,940, $1 \mathrm{mg} / \mathrm{kg}$ TCS-OX2-29, 1 mg/kg TCS-1102, 1 mg/kg CP55,940 + 1 mg/kg 
A

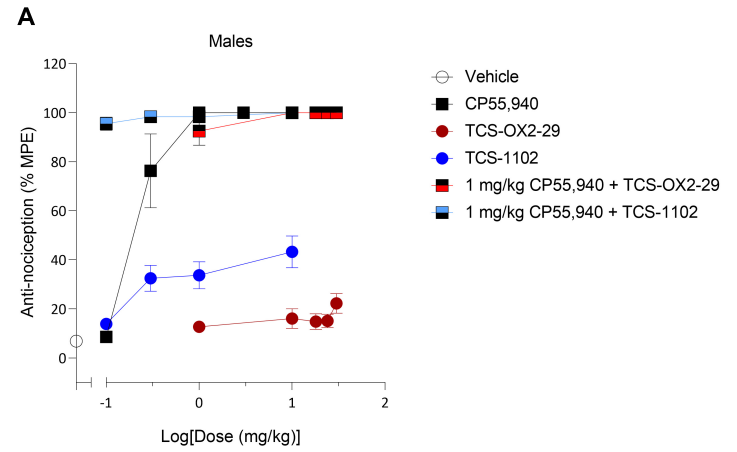

B

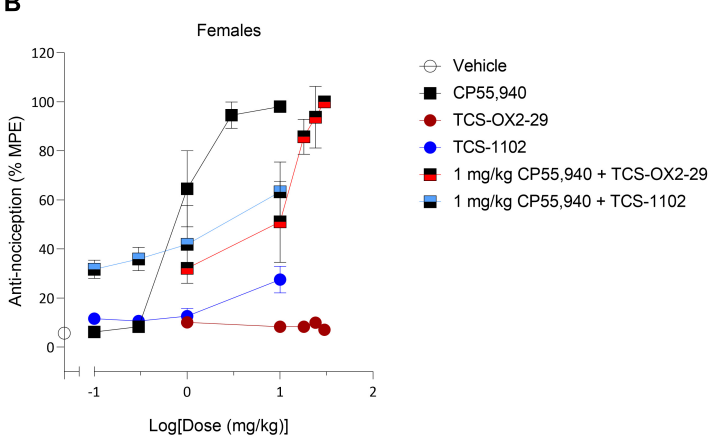

C

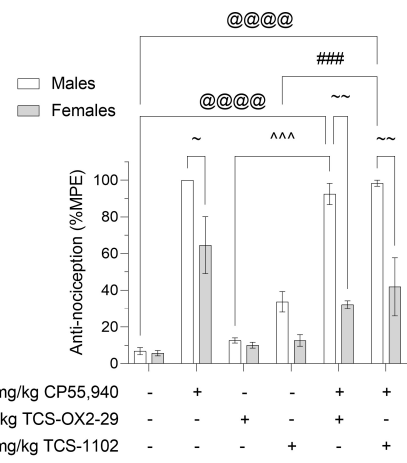

FIGURE 4 | Acute nociceptive effects as a result of cannabinoid and orexin drug treatments. Male (A) and female (B) C57BL/6 mice aged 6-12 weeks were i.p. administered one of the following dose ranges: CP55,940 (0.1-10 mg/kg), TCS-OX2-29 (1-30 mg/kg), TCS-1102 (0.1-10 mg/kg), $1 \mathrm{mg} / \mathrm{kg}$ CP55,940 + TCS-OX2-29 (1-30 mg/kg), or $1 \mathrm{mg} / \mathrm{kg}$ CP55,940 + TCS-1102 (0.1-10 mg/kg). 20 min post-injections, all mice underwent the tail flick test to assess anti-thermal nociception. (C) Anti-nociceptive responses were compared within (sex) and between (drugs) the following experimental groups: $1 \mathrm{mg} / \mathrm{kg}$ CP55,940, $1 \mathrm{mg} / \mathrm{kg}$ TCS-OX2-29, $1 \mathrm{mg} / \mathrm{kg}$ TCS-1102, $1 \mathrm{mg} / \mathrm{kg}$ CP55,940 + $1 \mathrm{mg} / \mathrm{kg}$ TCS-OX2-29, or $1 \mathrm{mg} / \mathrm{kg}$ CP55,940 + $1 \mathrm{mg} / \mathrm{kg}$ TCS-1102. All anti-nociceptive data are expressed as \%MPE (MPE = $20 \mathrm{~s})$, and as means \pm SEM. $n=6$ for all treatment groups. Significance was calculated using a two-way ANOVA followed by Tukey's post hoc analyses. @@@p $<0.001$ compared to Vehicle within sexes. ${ }^{m} p<0.001$ compared between $1 \mathrm{mg} / \mathrm{kg}$ TCS-OX2-29 and $1 \mathrm{mg} / \mathrm{kg}$ CP55,940 + $1 \mathrm{mg} / \mathrm{kg}$ TCS-OX2-29. \#\#\#p < 0.001 compared between $1 \mathrm{mg} / \mathrm{kg}$ TCS-1102 and

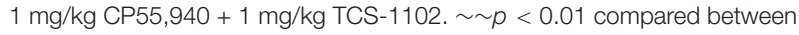
sexes, within treatment groups.
TABLE $3 \mid E D_{50}$ and $E_{\text {max }}$ values representing anti-nociception responses to cannabinoid and orexin drug treatments.

\begin{tabular}{|c|c|c|}
\hline \multirow[t]{2}{*}{ Treatment } & $E D_{50}(\mathrm{mg} / \mathrm{kg})(95 \% \mathrm{Cl})$ & $E_{\max }(\% \mathrm{MPE}) \pm \mathrm{SEM}$ \\
\hline & \multicolumn{2}{|c|}{ Males } \\
\hline CP55,940 & $0.19(0.11-0.31)$ & 100 \\
\hline TCS-OX2-29 & $>30$ & $22 \pm 4.0$ \\
\hline TCS-1102 & $7.3(3.4-15)$ & $41 \pm 4.7$ \\
\hline $\begin{array}{l}1 \mathrm{mg} / \mathrm{kg} \\
\text { CP55,940 + TCS-OX2-29 }\end{array}$ & n.c. & $100^{\wedge}$ \\
\hline \multirow[t]{2}{*}{$\begin{array}{l}1 \mathrm{mg} / \mathrm{kg} \\
\text { CP55,940 + TCS-1102 }\end{array}$} & n.c. & $100 \pm 1.6 \#$ \\
\hline & \multicolumn{2}{|c|}{ Females } \\
\hline CP55,940 & $0.76(0.48-1.2)$ & $98 \pm 1.9$ \\
\hline TCS-OX2-29 & n.c. & $8.3 \pm 1.8$ \\
\hline TCS-1102 & $>10$ & $28 \pm 5.5$ \\
\hline $\begin{array}{l}1 \mathrm{mg} / \mathrm{kg} \\
\text { CP55,940 + TCS-OX2-29 }\end{array}$ & $3.8(2.0-7.2)^{\star}$ & $100^{\wedge}$ \\
\hline $\begin{array}{l}1 \mathrm{mg} / \mathrm{kg} \\
\text { CP55,940 + TCS-1102 }\end{array}$ & $1.0(0.46-2.3) \#$ & $72 \pm 25 \#$ \\
\hline
\end{tabular}

Data were fit to a three parameter non-linear regression with a system minimum and maximum constrained to 0 and 100, respectively (GraphPad, Prism, v. 8.0). n.c., not converged.

For data without a clear dose-response (i.e., "n.c."), $E_{\max }$ is reported as the maximum response observed.

Data are expressed as $\mathrm{mg} / \mathrm{kg}$ with $95 \% \mathrm{Cl}$ or \%MPE \pm SEM.

${ }^{*} p<0.05$ compared to $1 \mathrm{mg} / \mathrm{kg}$ CP55,940 within sexes, $\hat{p}<0.05$ compared between $1 \mathrm{mg} / \mathrm{kg}$ TCS-OX2-29 and $1 \mathrm{mg} / \mathrm{kg}$ CP55,940 + $1 \mathrm{mg} / \mathrm{kg}$ TCS-OX229, and \#p < 0.05 compared between $1 \mathrm{mg} / \mathrm{kg}$ TCS-1102 and $1 \mathrm{mg} / \mathrm{kg}$ CP55,940 + $1 \mathrm{mg} / \mathrm{kg}$ TCS-1102, as determined by non-overlapping 95\% Cl or two-way ANOVA followed by Tukey's post hoc test.

Corresponding graph is presented in Figure 4.

TCS-OX2-29, and $1 \mathrm{mg} / \mathrm{kg}$ CP55,940 + $1 \mathrm{mg} / \mathrm{kg}$ TCS1102. Immunohistochemical experiments focused on two brain regions: (1) ventral striatum, a brain region thought to facilitate cataleptic effects (Turski et al., 1984; Ossowska et al., 1990; Anderson et al., 1996) and (2) primary motor cortex, a region that largely initiates and modulates locomotion (Sahni et al., 2020). In the ventral striatum, more whole-cell CB1ROX1R colocalization was observed in males treated with $1 \mathrm{mg} / \mathrm{kg}$ TCS-OX2-29 compared to males treated with the combination of $1 \mathrm{mg} / \mathrm{kg}$ CP55,940 + $1 \mathrm{mg} / \mathrm{kg}$ TCS-OX229; this difference was not seen in treatment-matched females (Figure 6A). Between males and females treated with $1 \mathrm{mg} / \mathrm{kg}$ TCS-OX2-29, ventral striatum tissue from males had higher CB1R-OX1R colocalization (Figure 6A). In both sexes, CB1ROX1R colocalization in the ventral striatum was greater

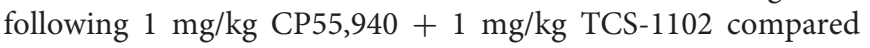
to both $1 \mathrm{mg} / \mathrm{kg}$ CP55,940 alone and $1 \mathrm{mg} / \mathrm{kg}$ TCS -1102 alone (Figure 6B); this is further illustrated by representative images (Figure 6E). No sex differences were observed within the TCS-1102-treated groups with regards to CB1R-OX1R colocalization in the ventral striatum (Figure 6B). In the primary motor cortex, there were no significant differences in CB1ROX1R colocalization between any of the experimental groups (Figures 7A,B,E).

In both sexes, CB1R-OX2R colocalization in the ventral striatum was higher in $1 \mathrm{mg} / \mathrm{kg}$ TCS-OX2-29-treated mice 


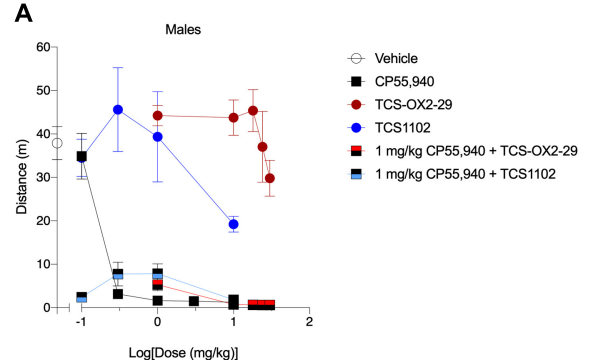

C
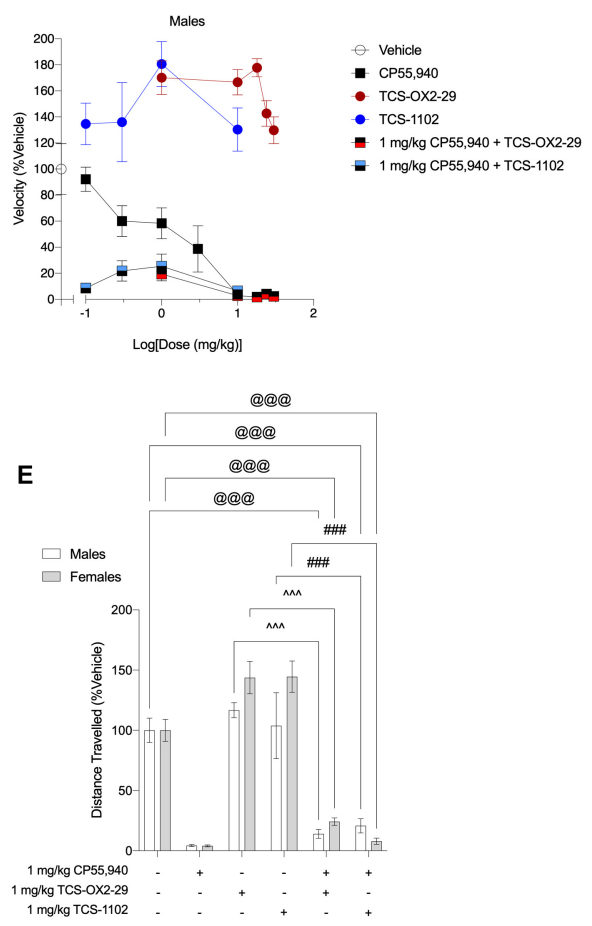

G

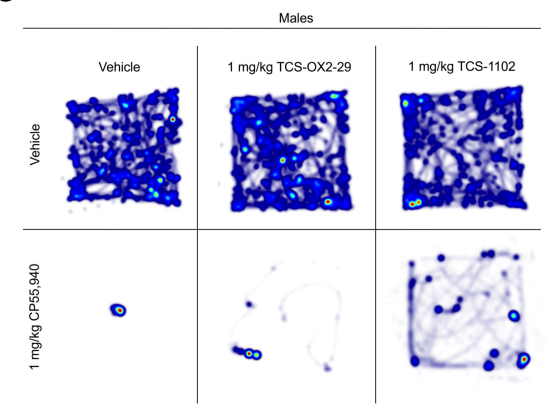

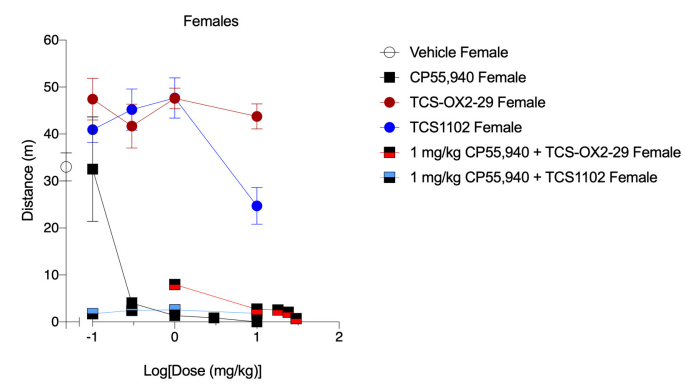

D

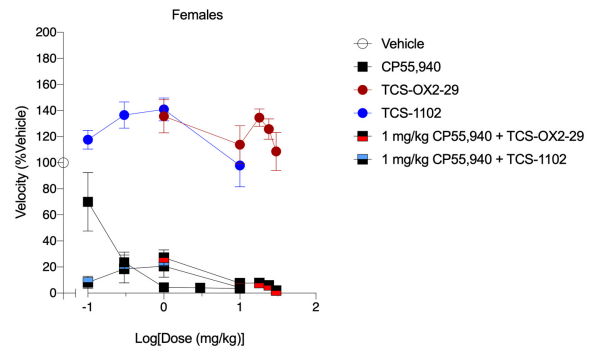

$\mathbf{F}$

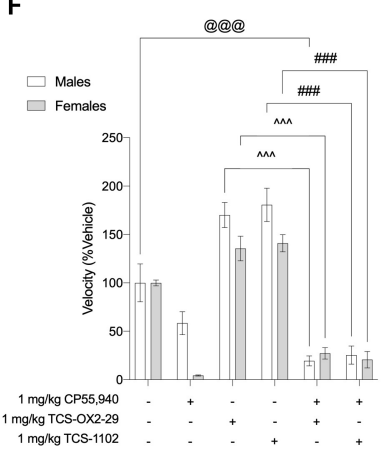

H

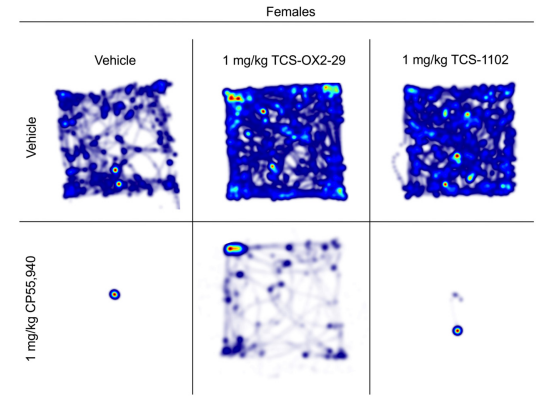

FIGURE 5 | Acute anti-locomotive effects from cannabinoid and orexin drug treatments. (A-D) Male and female C57BL/6 mice aged 6-12 weeks were i.p. administered one of the following dose ranges: CP55,940 (0.1-10 mg/kg), TCS-OX2-29 (1-30 mg/kg), TCS-1102 (0.1-10 mg/kg), $1 \mathrm{mg} / \mathrm{kg}$

CP55,940 + TCS-OX2-29 (1-30 mg/kg), or $1 \mathrm{mg} / \mathrm{kg}$ CP55,940 + TCS-1102 (0.1-10 mg/kg). $25 \mathrm{~min}$ post-injections, all mice underwent the open field test to assess locomotion. Distance traveled (E) and average velocity (F) were compared within (sex) and between (drugs) the following experimental groups: $1 \mathrm{mg} / \mathrm{kg}$ CP55,940, $1 \mathrm{mg} / \mathrm{kg}$ TCS-OX2-29, 1 mg/kg TCS-1102, 1 mg/kg CP55,940 + 1 mg/kg TCS-OX2-29, or 1 mg/kg CP55,940 + 1 mg/kg TCS-1102. All anti-locomotive data are expressed as $\mathrm{m}$ or $\mathrm{cm} / \mathrm{s}$, and as means \pm SEM. $n=6$ for all treatment groups. Significance was calculated using a two-way ANOVA followed by Tukey's post hoc analyses. @@@p 0.001 compared to Vehicle within sexes. ${ }^{m} p<0.001$ compared between 1 mg/kg TCS-OX2-29 and 1 mg/kg CP55,940 + 1 mg/kg TCS-OX2-29. \#\#\#p < 0.001 compared between $1 \mathrm{mg} / \mathrm{kg}$ TCS-1102 and $1 \mathrm{mg} / \mathrm{kg}$ CP55,940 + $1 \mathrm{mg} / \mathrm{kg}$ TCS-1102. (G,H) Representative heat maps illustrating the locomotion of male (G) and female (H) C57BL/6 mice treated with either $1 \mathrm{mg} / \mathrm{kg}$ CP55,940, $1 \mathrm{mg} / \mathrm{kg}$ TCS-OX2-29, $1 \mathrm{mg} / \mathrm{kg}$ TCS-1102, $1 \mathrm{mg} / \mathrm{kg}$ CP55,940 + 1 mg/kg TCS-OX2-29, or 1 mg/kg CP55,940 + 1 mg/kg TCS-1102. 
TABLE $4 \mid E D_{50}$ and $E_{\text {max }}$ values summarizing cannabinoid- and orexin-induced locomotion responses.

\begin{tabular}{|c|c|c|c|c|}
\hline \multirow[t]{3}{*}{ Treatment } & Distance traveled & Average velocity & Distance traveled (\%Vehicle) & Average velocity (\%Vehicle) \\
\hline & \multicolumn{2}{|c|}{$E D_{50}(\mathrm{mg} / \mathrm{kg})(95 \% \mathrm{Cl})$} & \multicolumn{2}{|c|}{$E_{\max } \pm \mathrm{SEM}$} \\
\hline & \multicolumn{4}{|c|}{ Males } \\
\hline CP55,940 & $<0.10$ & $0.51(0.10-3.0)$ & $3.3 \pm 0.41$ & $3.8 \pm 1.1$ \\
\hline TCS-OX2-29 & $>30$ & $>30$ & $77 \pm 11^{*}$ & $130 \pm 10^{\star}$ \\
\hline TCS-1102 & $19(0.10-3.0)$ & n.c. & $51 \pm 4.8^{*}$ & $130 \pm 17^{\star}$ \\
\hline $1 \mathrm{mg} / \mathrm{kg}$ CP55,940 + TCS-OX2-29 & n.c. & n.c. & $1.0 \pm 2.1^{\wedge}$ & $1.7 \pm 3.2^{\wedge}$ \\
\hline \multirow[t]{2}{*}{1 mg/kg CP55,940 + TCS-1102 } & n.c. & n.c. & $15 \pm 5.3$ & $17 \pm 6.6 \#$ \\
\hline & \multicolumn{4}{|c|}{ Females } \\
\hline CP55,940 & $<0.10$ & $<0.10$ & 0 & $0.68 \pm 7.4$ \\
\hline TCS-OX2-29 & n.c. & n.c. & $122 \pm 25^{\star}$ & $109 \pm 15^{\star}$ \\
\hline TCS-1102 & $6.1(0.10-3.0)$ & n.c. & $75 \pm 12^{\star}$ & $98 \pm 16^{\star}$ \\
\hline $1 \mathrm{mg} / \mathrm{kg}$ CP55,940 + TCS-OX2-29 & n.c. & n.c. & $0.63 \pm 5.2^{\wedge}$ & $1.2 \pm 5.7^{\wedge}$ \\
\hline $1 \mathrm{mg} / \mathrm{kg}$ CP55,940 + TCS-1102 & n.c. & n.c. & $7.0 \pm 1.6 \#$ & $14 \pm 7.0 \#$ \\
\hline
\end{tabular}

Distance traveled (a) and average velocity (b) in the open field test were the measures of anti-locomotion.

Data were fit to a three parameter non-linear regression with a system minimum and maximum constrained to 0 and 100, respectively (GraphPad, Prism, v. 8.0).

For data without a clear dose-response (i.e., "n.c."), Emax is reported as the maximum response observed.

Data are expressed as $\mathrm{mg} / \mathrm{kg}$ with $95 \% \mathrm{Cl}$ or\%Vehicle \pm SEM.

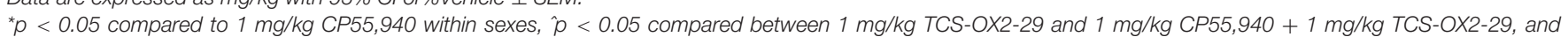

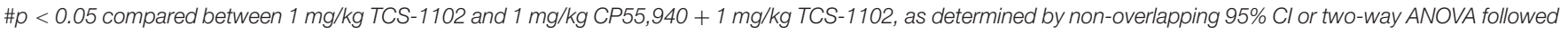
by Tukey's post hoc test. Corresponding graphs are presented in Figure 5.

compared to mice co-treated with $1 \mathrm{mg} / \mathrm{kg}$ CP $55,940+1 \mathrm{mg} / \mathrm{kg}$ TCS-OX2-29 (Figure 6C). Compared to females, ventral striatum tissue from males treated with $1 \mathrm{mg} / \mathrm{kg}$ TCS-OX2-29 had larger CB1R-OX2R colocalization (Figure 6C); this is demonstrated in the representative images (Figure 6F). There were no differences in ventral striatum CB1R-OX2R colocalization within or between any of the groups treated with TCS-1102 (Figure 6D). Moreover, the primary motor cortex did not display differences in CB1ROX2R colocalization between any of the experimental groups (Figures 7C,D,F). To summarize, $1 \mathrm{mg} / \mathrm{kg}$ CP55,940 + $1 \mathrm{mg} / \mathrm{kg}$ TCS-1102 was the only combination treatment that displayed higher CB1R-OX1R colocalization in the ventral striatum compared to its constituent drugs alone (Figure 6B). This supports the tetrad data, in which this combination treatment produced more catalepsy than each of its constituent drugs (Figure 1C). As for CB1R-OX2R colocalization in the ventral striatum, $1 \mathrm{mg} / \mathrm{kg}$ TCS-OX2-29 co-treatment was associated with more colocalization than the co-treatment with CP55,940 and TCS-OX2-29 (Figure 6C). Compared to OX2R antagonism, OX1R antagonism and subsequent changes in CB1R-OX1R colocalization following co-treatment with the CB1R agonist CP55,940 and the DORA TCS-1102 are likely to be the potentiators of catalepsy. None of the drug treatments produced significant CB1R-OX1R nor CB1R-OX2R colocalization changes in the primary motor cortex, which supports the lack of the CP55,940 and TCS-1102 additivity with regards to reduced movement in the open field test.

\section{DISCUSSION}

To date, the majority of endocannabinoid and orexin interaction studies have either characterized their molecular or physical interactions in vitro, or investigated their physiological interdependence in complex disease models related to sleep, appetite, and reward. One other study has assessed their dual modulation of body temperature, pain, locomotion, anxiety, and memory in healthy and transgenic male mice (Flores et al., 2016). The current study aimed to not only measure catalepsy alongside other measures of the tetrad, but utilize a full CB1R agonist and a clinically relevant DORA in both male and female mice. Compared to the CB1R partial agonist $\Delta^{9}$-THC, which was used by Flores et al. (2016), CP55,940 is a full agonist of CB1R (Howlett and Abood, 2017) that is well-documented to produce more potent and efficacious responses in vitro and in vivo (Patel et al., 2020; Zagzoog et al., 2020; Henderson-Redmond et al., 2021). In the current study, CP55,940 $(0.1-10 \mathrm{mg} / \mathrm{kg})$ produced similar dose-dependent sedative effects in both males and females.

The OX2R antagonist TCS-OX2-29 and the DORA TCS1102 were the orexin receptor compounds used in the current study. Treatment with either orexin receptor antagonist alone was associated with hypothermic, anti-nociceptive, and antilocomotive effects of smaller magnitude than that of CP55,940. TCS-1102 was generally more efficacious compared to TCS-OX229 , suggesting either a greater role for OX1R or both orexin receptor subtypes in controlling body temperature, nociception, and locomotion. In a previous study, OX1R antagonism via SB-334867 was found to potentiate $\Delta^{9}$-THC-induced hypothermia, anti-nociception, and anxiolytic-like effects, while OX2R antagonism by TCS-OX2-29 was not (Flores et al., 2016). The current study was more focused on evaluating a clinically relevant DORA in conjunction with a cannabinoid. DORAs such as Suvorexant and Lemborexant are used for insomnia as they cause sedation by blocking the arousing effects of endogenous orexins (Yoshimichi et al., 2001; Patel et al., 2015; 
A

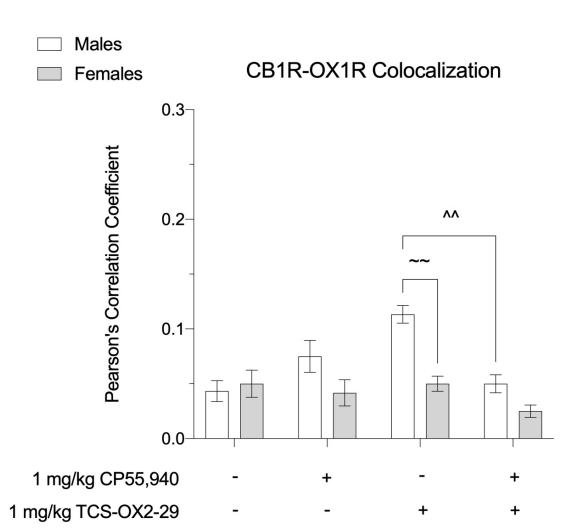

C

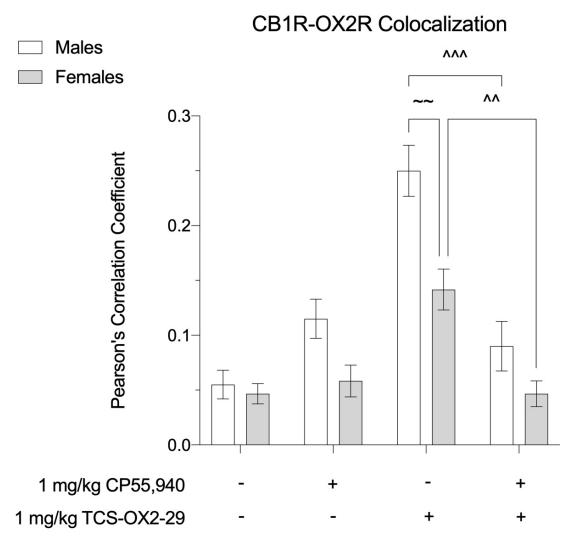

E
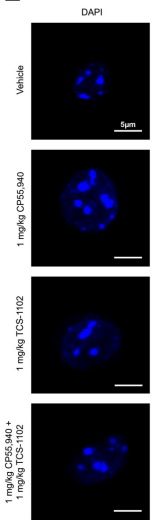
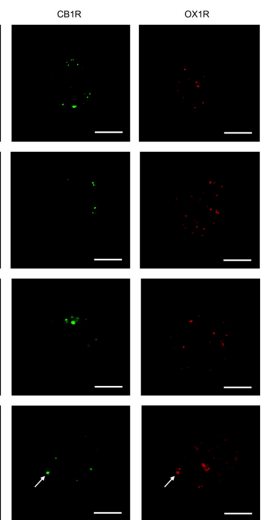
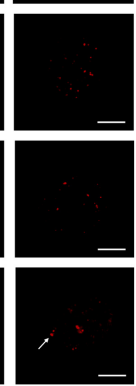
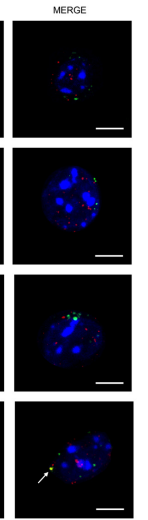

B

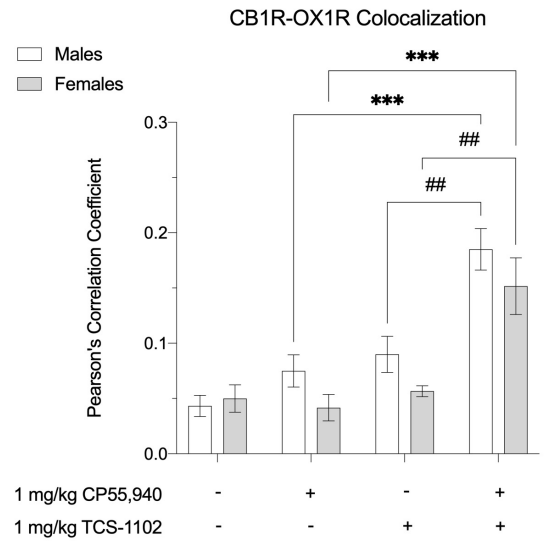

D

$\square$ Males
$\square$ Females $\quad$ CB1R-OX2R Colocalization

(2)

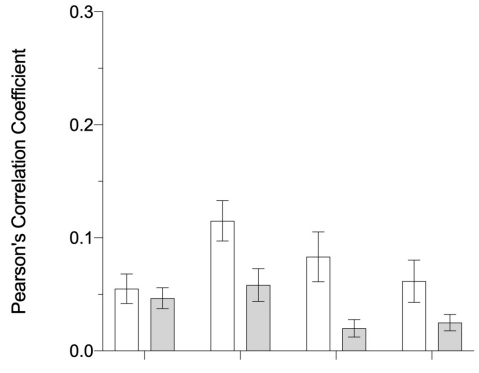

$1 \mathrm{mg} / \mathrm{kg}$ CP55,940

$1 \mathrm{mg} / \mathrm{kg}$ TCS-1102

$\mathbf{F}$
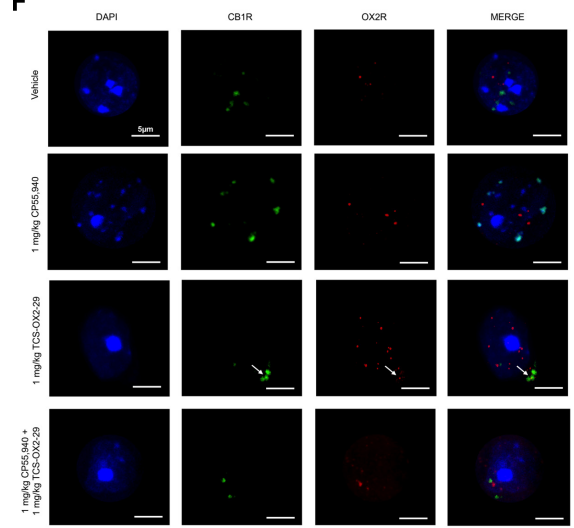

FIGURE 6 | CB1R-OX1R and CB1R-OX2R colocalization in the ventral striatum following cannabinoid and orexin drug treatments. Male and female C57BL/6 mice aged 6-12 weeks were i.p. administered one of the following dose ranges: CP55,940 (0.1-10 mg/kg), TCS-OX2-29 (1-30 mg/kg), TCS-1102 (0.1-10 mg/kg), $1 \mathrm{mg} / \mathrm{kg}$ CP55,940 + TCS-OX2-29 (1-30 mg/kg), or 1 mg/kg CP55,940 + TCS-1102 (0.1-10 mg/kg). 30 min post-injections, mice were euthanized, perfused, and their brains collected for immunohistochemistry. Colocalization between CB1R and OX1R (A,B) and CB1R and OX2R (C,D) was compared within (sex) and between (drugs) the following experimental groups: $1 \mathrm{mg} / \mathrm{kg}$ CP55,940, $1 \mathrm{mg} / \mathrm{kg}$ TCS-OX2-29, 1 mg/kg TCS-1102, $1 \mathrm{mg} / \mathrm{kg}$ CP55,940 + 1 mg/kg TCS-OX2-29, or $1 \mathrm{mg} / \mathrm{kg}$ CP55,940 $+1 \mathrm{mg} / \mathrm{kg}$ TCS-1102. All colocalization data are expressed as Pearson's Correlation Coefficients, and as means \pm SEM. $n=6$ (cells) for all treatment groups. Significance was calculated using a two-way ANOVA followed by Tukey's post hoc analyses. ${ }^{* \star \star} p<0.001$ compared to 1 mg/kg CP55,940 within sexes. $m / m p<0.01 / 0.001$ compared between $1 \mathrm{mg} / \mathrm{kg}$ TCS-OX2-29 and $1 \mathrm{mg} / \mathrm{kg}$ CP55,940 + $1 \mathrm{mg} / \mathrm{kg}$ TCS-OX2-29. \#\#p < 0.01 compared between $1 \mathrm{mg} / \mathrm{kg}$ TCS-1102 and $1 \mathrm{mg} / \mathrm{kg}$ CP55,940 $+1 \mathrm{mg} / \mathrm{kg}$ TCS-1102. p < 0.01 compared between sexes, within treatment groups. (E) Representative images corresponding to panels (A,B) for CB1R-OX1R colocalization. (F) Representative images corresponding to panels (C,D) for CB1R-OX2R colocalization. 
A

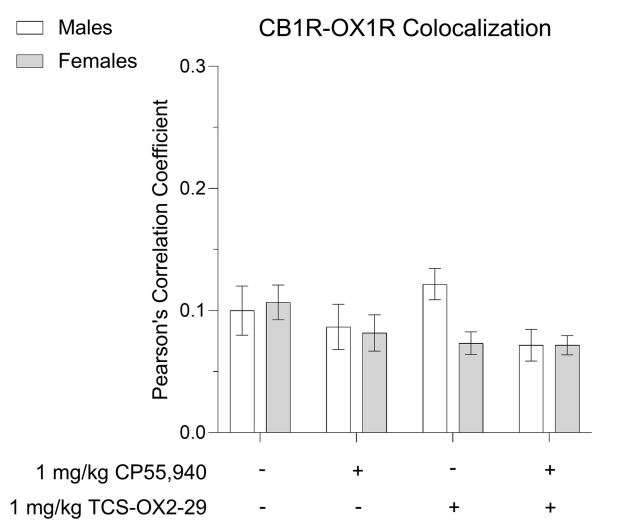

C

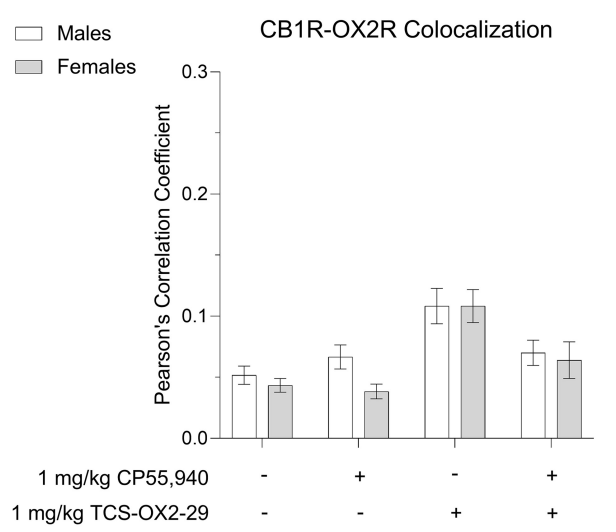

E
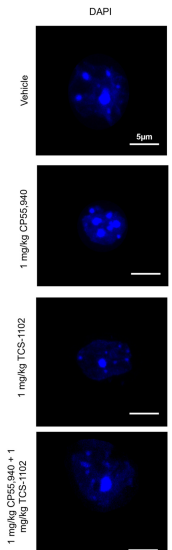
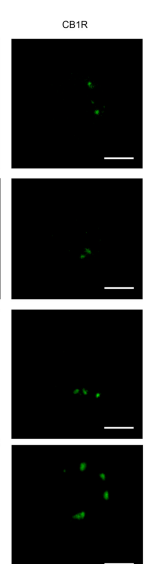
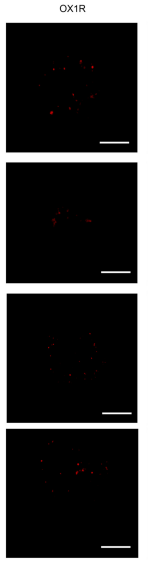
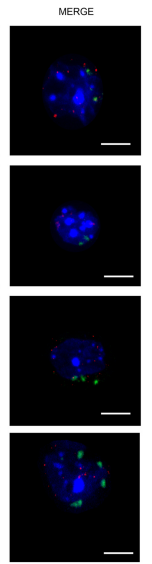

B

$\square$ Males CB1R-OX1R Colocalization

$\square$ Females 0.3

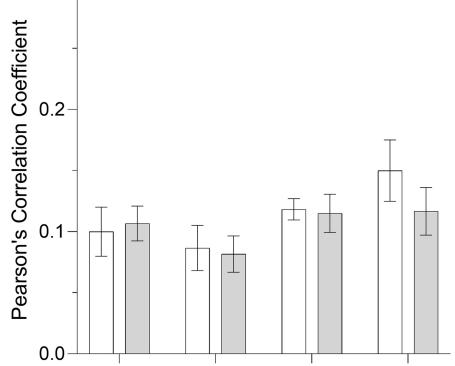

$1 \mathrm{mg} / \mathrm{kg}$ CP55,940

$1 \mathrm{mg} / \mathrm{kg}$ TCS-1102

D

$\square$ Males $\quad$ CB1R-OX2R Colocalization
$\square$ Females $0.3-$

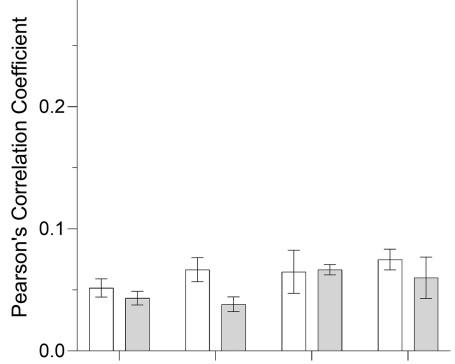

$1 \mathrm{mg} / \mathrm{kg}$ CP55,940

$1 \mathrm{mg} / \mathrm{kg}$ TCS-1102

$\mathbf{F}$
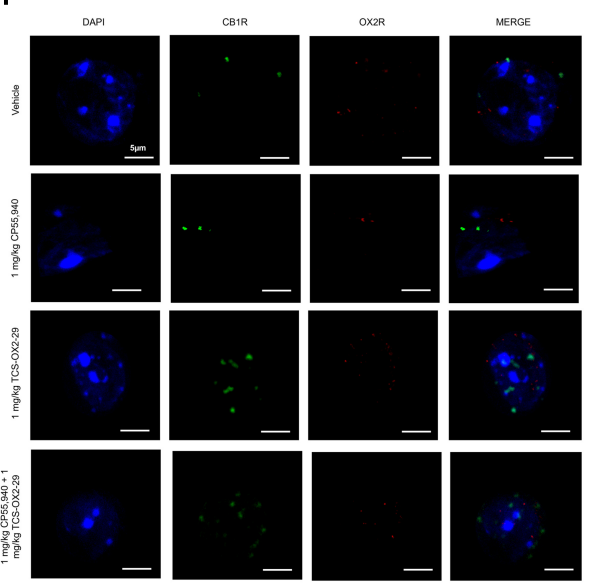

FIGURE 7 | CB1R-OX1R and CB1R-OX2R colocalization in the primary motor cortex following cannabinoid and orexin drug treatments. Male and female C57BL/6 mice aged 6-12 weeks were i.p. administered one of the following dose ranges: CP55,940 (0.1-10 mg/kg), TCS-OX2-29 (1-30 mg/kg), TCS-1102 (0.1-10 mg/kg), 1 mg/kg CP55,940 + TCS-OX2-29 (1-30 mg/kg), or 1 mg/kg CP55,940 + TCS-1102 (0.1-10 mg/kg). 30 min post-injections, mice were euthanized, perfused, and their brains collected for immunohistochemistry. Colocalization between CB1R and OX1R (A,B) and CB1R and OX2R (C,D) was compared within (sex) and between (drugs) the following experimental groups: $1 \mathrm{mg} / \mathrm{kg}$ CP55,940, $1 \mathrm{mg} / \mathrm{kg}$ TCS-OX2-29, $1 \mathrm{mg} / \mathrm{kg}$ TCS-1102, $1 \mathrm{mg} / \mathrm{kg}$ CP55,940 + $1 \mathrm{mg} / \mathrm{kg}$ TCS-OX2-29, or $1 \mathrm{mg} / \mathrm{kg}$ CP55,940 + $1 \mathrm{mg} / \mathrm{kg}$ TCS-1102. All colocalization data are expressed as Pearson's Correlation Coefficients, and as means \pm SEM. $n=6$ (cells) for all treatment groups. Significance was calculated using a two-way ANOVA followed by Tukey's post hoc analyses. (E) Representative images corresponding to panels (A,B) for CB1R-OX1R colocalization. (F) Representative images corresponding to panels $\mathbf{( C , D )}$ for CB1R-OX2R colocalization. 
Herring et al., 2019). Comparisons between the orexin receptor subtypes in the context of the sleep-wake cycle have determined that although OX2R is more critical in inducing arousal, OX1R plays additional roles in promoting and maintaining wakefulness (Mieda et al., 2011; Mang et al., 2012).

Aside from catalepsy, co-manipulation of both cannabinoid and orexin receptors did not alter responses in the tetrad battery of assays compared to cannabinoid agonism alone. Thus, CP55,940-induced hypothermia, anti-nociception, and anti-locomotion are not regulated by OX1R- nor OX2R. Based on the dose-response curves for the co-treatments of CP55,940 and each of the orexin receptor antagonists, it can be confirmed that additivity between these two drug types with regards to hypothermia, anti-nociception, and anti-locomotion, does not exist at any dose. In terms of non-heterodimerized, noninteracting cannabinoid and orexin receptors, these results suggest that CBRs have a greater physiological role than orexin receptors in (1) the preoptic anterior hypothalamus and control of body temperature (Rawls et al., 2002), (2) spine and periaqueductal gray area underlying nociception (Freund et al., 2003; Walker and Hohmann, 2005), and (3) cortical regions in modulating locomotion (Polissidis et al., 2013). CB1R remains one of the most abundant GPCRs in the CNS (Mackie, 2005; Kano et al., 2009). Orexin receptor mRNA is also found in these regions (Trivedi et al., 1998; Marcus et al., 2001), however, there are no studies comparing the relative abundance of cannabinoid and orexin receptors in the same samples.

Unlike body temperature, nociception, and locomotion, cotreatment with CP55,940 and TCS-1102 produced longer-lasting catalepsy than CP55,940 or TCS-1102 alone, demonstrating additivity where each drug had an equal role in producing catalepsy. This was not observed for the combination of CP55,940 and TCS-OX2-29, suggesting that OX1R antagonism is more critical in potentiating CP55,940-induced catalepsy. Additivity between these two drugs may be better explained by regional differences in CB1R-OX1R and CB1R-OX2R interactions or heterodimerization in the ventral striatum, a sub-cortical region that expresses all three receptor subtypes to modulate catalepsy (Turski et al., 1984; Ossowska et al., 1990; Flores et al., 2013). Beyond the ventral striatum, orexin receptors are sparse in the dorsal striatum and more densely expressed in the ventral striatum (Hervieu et al., 2001; Marcus et al., 2001; Mackie, 2005; Flores et al., 2013). Our current study used colocalization as a proof-of-concept for the main behavioral data; thus aimed to efficiently gather data from brain regions that are well-documented co-expressed both receptor types. Moreover, the nucleus accumbens and the olfactory tubercle (which composes the ventral striatum) expresses both CB1R and OX2R (Flores et al., 2013). Although the nucleus accumbens is known to process emotions and reward, it also integrates emotional or motivational stimuli as it relates to sedation (Valencia Garcia and Fort, 2018). Anti-locomotion is a focal point in our current study because both cannabinoids and orexin drugs cause sedation. The olfactory tubercle processes incoming sensory information which may include rewarding stimuli (Wesson and Wilson, 2011; Murata, 2020). When CBRs and OX1R were co-manipulated in the current study, there was more CB1R-OX1R colocalization in the ventral striatum. Similar observations have been made in recombinant cell cultures, where the OX1R antagonist SB-674042 and CB1R antagonist SR141716A alone caused relocalization of OX1R and CB1R together (Ellis et al., 2006). Neither of these antagonists had significant affinities for the other receptor type, suggesting that inhibiting one receptor type caused relocalization of the other by physical proxy (Ellis et al., 2006).

Sex differences were observed in two scenarios. First, male C57BL/6 mice were more sensitive to the cataleptic effects of $1 \mathrm{mg} / \mathrm{kg}$ C55,940 + $1 \mathrm{mg} / \mathrm{kg}$ TCS-1102 compared to treatmentmatched females. Sex differences in catalepsy were not detected in the TCS-OX2-29-administered groups, indicating that males are more sensitive than females to simultaneous CBR and OX1Rbut not OX2R-manipulation. Closer examination of the receptor colocalization results revealed that in the absence of cannabinoid and orexin drug administration, males and females had similar levels of CB1R-OX1R and CB1R-OX2R expression in the ventral striatum. Following treatment with TCS-OX2-29 alone, cells from the ventral striatum of males had higher levels of CB1ROX1R/OX2R colocalization compared to females. In all other drug treatments, no significant difference in cannabinoid and orexin receptor colocalization was observed between sexes. Male rodents have lower hypothalamic mRNA levels of OXA and OXB precursor, prepro-orexin (Jöhren et al., 2002), as well as less basal activation of OXA containing lateral hypothalamic neurons (Grafe et al., 2017). Although female rodents are reported to have higher orexigenic functioning (Grafe and Bhatnagar, 2020), males may have greater expression and function of orexin receptors that interact, or are heterodimerized with CB1R. This may result in males being more sensitive to dual cannabinoid and orexin drug effects compared to females.

The second sex difference observed was within the tail flick test. Males were more sensitive to the analgesic effects of CP55,940 alone, as well as both combination drug treatments. Most behavioral studies have reported that females are more sensitive to the cataleptic and anti-nociceptive effects of phytoand synthetic cannabinoid agonists (Tseng and Craft, 2001; Wiley et al., 2017). With regards to brain region-specific cannabinoid receptor expression and function, CB1R density is greater in the prefrontal cortex of male versus female rats (Castelli et al., 2014). Males also display higher CB1R binding in limbic regions such as the striatum (Rodríguez de Fonseca et al., 1994). It remains unclear how these molecular data translate to sex-dependent behavioral outcomes, as these types of experiments have never been conducted nor correlated in the same sample or study. Preclinical cannabinoid research is seeing more inclusion of female animals; however, endocannabinoidsex hormone interactions are more complex than simply comparing testosterone-dominant males and estrogen-dominant females (Struik et al., 2018). The latter undergo hypothalamicpituitary-gonadal-driven ovulation cycles that cause significant fluctuations in circulating estrogens and progestins. The mouse estrus cycle spans 4 days, throughout which these hormone levels influence endocannabinoid activity and physiological response to cannabinoids (Rodríguez de Fonseca et al., 1994; Wakley and Craft, 2011). For example, female rats in estrus are significantly 
less sensitive to the sedative and analgesic effects of systemic $\Delta^{9}$ THC compared to female rats in late proestrus (Wakley and Craft, 2011). Estrus cycle-dependent differences in cannabinoid and orexin drug responses are being investigated in a forthcoming proof-of-concept study.

Cannabis is one of the most highly consumed psychoactive drugs in the world (World Health Organization [WHO], 2016). Many people self-medicate with cannabis to induce relaxation; a subset of these individuals may co-administer cannabis with prescribed DORAs for insomnia. Sleep is a complicated behavior based on multiple physiological factors. Although both cannabinoid receptor agonists and orexin receptor antagonists individually promote sleep, they may differentially affect the conditions for sleep when combined. The current study found that catalepsy was the only tetrad measure equally potentiated by both drugs. Moreover, OX1R antagonism, rather than OX2R antagonism, resulted in increased CB1R-OX1R colocalization in the ventral striatum underlying this cataleptic additivity. The growing use of cannabinoids warrants more research in the area of cannabinoid-drug interactions. Knowledge of cannabinoid receptor heterodimerization with other GPCRs is key in understanding these pharmacodynamic interactions.

\section{DATA AVAILABILITY STATEMENT}

The raw data supporting the conclusions of this article will be made available by the authors, without undue reservation.

\section{ETHICS STATEMENT}

The animal study was reviewed and approved by Animal Research Ethics Board and the Scientific Merit Review

\section{REFERENCES}

Anderson, J. J., Kask, A. M., and Chase, T. N. (1996). Effects of cannabinoid receptor stimulation and blockade on catalepsy produced by dopamine receptor antagonists. Eur. J. 295, 163-168. doi: 10.1016/0014-2999(95)00 661-3

Babson, K. A., Sottile, J., and Morabito, D. (2017). Cannabis, cannabinoids, and sleep: a review of the literature. Curr. Psychiatry Rep. 19:23. doi: 10.1007/ s11920-017-0775-9

Berrendero, F., Flores, Á., and Robledo, P. (2018). When orexins meet cannabinoids: bidirectional functional interactions. Biochem. Pharmacol. 157, 43-50. doi: 10.1016/j.bcp.2018.08.040

Castelli, M. P., Fadda, P., Casu, A., Spano, M. S., Casti, A., Fratta, W., et al. (2014). Male and female rats differ in brain cannabinoid CB1 receptor density and function and in behavioural traits predisposing to drug addiction: effect of ovarian hormones. Curr. Pharm. Des. 20, 2100-2113. doi: 10.2174/ 13816128113199990430

Chiou, L. C., Lee, H. J., Ho, Y. C., Chen, S., Liao, Y. Y., Ma, C. H., et al. (2010). Orexins/hypocretins: pain regulation and cellular actions. Curr. Pharm. Des. 16, 3089-3100. doi: 10.2174/138161210793292483

Ellis, J., Pediani, J. D., Canals, M., Milasta, S., and Milligan, G. (2006). Orexin-1 receptor-cannabinoid $\mathrm{CB} 1$ receptor heterodimerization results in both liganddependent and -independent coordinated alterations of receptor localization and function. J. Biol. Chem. 281, 38812-38824. doi: 10.1074/jbc.M602494200
Committee for Animal Behaviour at the University of Saskatchewan.

\section{AUTHOR CONTRIBUTIONS}

HJK designed and executed the experiments, analyzed the data, as well as wrote and edited the manuscript. AZ, AMS, UCE, $\mathrm{MJB}$, and TH assisted with in vivo experiments and edited the manuscript. RBL aided in the design of the experiments, analyzed the data, and edited the manuscript.

\section{FUNDING}

This work was supported by the National Sciences and Engineering Research Council (NSERC) Discovery Grant (DGECR-2019-00207) held by RBL. AZ and UCE were supported by graduate scholarships from the College of Pharmacy and Nutrition, University of Saskatchewan. AMS was supported by an interdisciplinary undergraduate research award from the College of Medicine and College of Pharmacy and Nutrition, University of Saskatchewan.

\section{ACKNOWLEDGMENTS}

We thank Aditya Manek from the University of Saskatchewan Histology Core Facility for his guidance in developing the cryosectioning and immunohistochemistry protocols. We also thank Narsimha Pujari in the Western College of Veterinary Medicine at the University of Saskatchewan, for his assistance in confocal microscopy and colocalization analysis.

Flores, A., Maldonado, R., and Berrendero, F. (2013). Cannabinoid-hypocretin cross-talk in the central nervous system: what we know so far. Front. Neurosci. 7:256. doi: 10.3389/fnins.2013.00256

Flores, Á., Maldonado, R., and Berrendero, F. (2014). The hypocretin/orexin receptor-1 as a novel target to modulate cannabinoid reward. Biol. Psychiatry 75, 499-507. doi: 10.1016/j.biopsych.2013.06.012

Flores, Á, Julià-Hernández, M., Maldonado, R., and Berrendero, F. (2016). Involvement of the orexin/hypocretin system in the pharmacological effects induced by $\Delta$ 9-tetrahydrocannabinol. Br. J. Pharmacol. 173, 1381-1392. doi: 10.1111/bph. 13440

Freund, T. F., Katona, I., and Piomelli, D. (2003). Role of endogenous cannabinoids in synaptic signaling. Physiol. Rev. 83, 1017-1066. doi: 10.1152/physrev.00004. 2003

Funato, H., Tsai, A. L., Willie, J. T., Kisanuki, Y., Williams, S. C., Sakurai, T., et al. (2009). Enhanced orexin receptor-2 signaling prevents diet-induced obesity and improves leptin sensitivity. Cell Metab. 9, 64-76. doi: 10.1016/j.cmet.2008.1 0.010

Grafe, L. S., and Bhatnagar, S. (2020). The contribution of orexins to sex differences in the stress response. Brain Res. 1731:145893. doi: 10.1016/j.brainres.2018.0 7.026

Grafe, L. A., Eacret, D., Luz, S., Gotter, A. L., Renger, J. J., Winrow, C. J., et al. (2017). Orexin 2 receptor regulation of the hypothalamic-pituitary-adrenal (HPA) response to acute and repeated stress. Neuroscience 348, 313-323. doi: 10.1016/j.neuroscience.2017.02.038 
Henderson-Redmond, A. N., Sepulveda, D. E., Ferguson, E. L., Kline, A. M., Piscura, M. K., and Morgan, D. J. (2021). Sex-specific mechanisms of tolerance for the cannabinoid agonists CP55,940 and delta-9-tetrahydrocannabinol $\left(\Delta^{9}\right.$. THC). Psychopharmacology doi: 10.1007/s00213-021-05886-9 [Epub Online ahead of print].

Herring, W. J., Roth, T., Krystal, A. D., and Michelson, D. (2019). Orexin receptor antagonists for the treatment of insomnia and potential treatment of other neuropsychiatric indications. J. Sleep Res. 28:e12782. doi: 10.1111/jsr.12782

Hervieu, G. J., Cluderay, J. E., Harrison, D. C., Roberts, J. C., and Leslie, R. A. (2001). Gene expression and protein distribution of the orexin-1 receptor in the rat brain and spinal cord. Neuroscience 103, 777-797. doi: 10.1016/s03064522(01)00033-1

Hilairet, S., Bouaboula, M., Carrière, D., Le Fur, G., and Casellas, P. (2003). Hypersensitization of the orexin 1 receptor by the CB1 receptor: evidence for cross-talk blocked by the specific CB1 antagonist, SR141716. J. Biol. Chem. 278, 23731-23737. doi: 10.1074/jbc.M212369200

Howlett, A. C., and Abood, M. E. (2017). CB1 \& CB2 receptor pharmacology. Adv. Pharmacol. 80, 169-206. doi: 10.1016/bs.apha.2017.03.007

Imperatore, R., Palomba, L., Morello, G., Spiezio, A. D., Piscitelli, F., Marzo, V. D., et al. (2016). Formation of OX-1R/CB1R heteromeric complexes in embryonic mouse hypothalamic cells: effect on intracellular calcium, 2-arachidonoylglycerol biosynthesis and ERK phosphorylation. Pharmacol. Res. 111, 600-609. doi: $10.1016 /$ j.phrs.2016.07.009

Jäntti, M. H., Mandrika, I., and Kukkonen, J. P. (2014). Human orexin/hypocretin receptors form constitutive homo- and heteromeric complexes with each other and with human CB1 cannabinoid receptors. Biochem. Biophys. Res. Commun. 445, 486-490. doi: 10.1016/j.bbrc.2014.02.026

Jöhren, O., Neidert, S. J., Kummer, M., and Dominiak, P. (2002). Sexually dimorphic expression of prepro-orexin mRNA in the rat hypothalamus. Peptides 23, 1177-1180. doi: 10.1016/S0196-9781(02)00052-9

Kano, M., Ohno-Shosaku, T., Hashimotodani, Y., Uchigashima, M., and Watanabe, M. (2009). Endocannabinoid-mediated control of synaptic transmission. Physiol. Rev. 89, 309-380. doi: 10.1152/physrev.00019.2008

Kilkenny, C., Browne, W. J., Cuthill, I. C., Emerson, M., and Altman, D. G. (2010). Improving bioscience research reporting: the arrive guidelines for reporting animal research. PLoS Biol. 8:e1000412. doi: 10.1371/journal.pbio.1000412

Mackie, K. (2005). "Distribution of cannabinoid receptors in the central and peripheral nervous system," in Cannabinoids, ed. R. G. Pertwee (Heidelberg: Springer), 299-325.

Mang, G. M., Dürst, T., Bürki, H., Imobersteg, S., Abramowski, D., Schuepbach, E., et al. (2012). The dual orexin receptor antagonist almorexant induces sleep and decreases orexin-induced locomotion by blocking orexin 2 receptors. Sleep 35, 1625-1635. doi: 10.5665/sleep.2232

Marcus, J. N., Aschkenasi, C. J., Lee, C. E., Chemelli, R. M., Saper, C. B., Yanagisawa, M., et al. (2001). Differential expression of Orexin receptors 1 and 2 in the rat brain. J. Comp. Neurol. 435, 6-25. doi: 10.1002/cne.1190

Mechoulam, R., and Fride, E. (2001). Physiology: a hunger for cannabinoids. Nature 410, 763-765. doi: 10.1038/35071214

Merroun, I., El Mlili, N., Martinez, R., Porres, J. M., Llopis, J., Ahabrach, H., et al. (2015). Interaction between orexin A and cannabinoid system in the lateral hypothalamus of rats and effects of subchronic intraperitoneal administration of cannabinoid receptor inverse agonist on food intake and the nutritive utilization of protein. J. Physiol. Pharmacol. 66, 181-190.

Metna-Laurent, M., Mondésir, M., Grel, A., Vallée, M., and Piazza, P. V. (2017). Cannabinoid-induced tetrad in mice. Curr. Protoc. Neurosci. 80, 9.59.1-9.59.10. doi: $10.1002 / \mathrm{cpns} .31$

Mieda, M., Hasegawa, E., Kisanuki, Y. Y., Sinton, C. M., Yanagisawa, M., and Sakurai, T. (2011). Differential roles of orexin receptor-1 and -2 in the regulation of Non-REM and REM sleep. J. Neurosci. 31, 6518-6526. doi: 10. 1523/JNEUROSCI.6506-10.2011

Monda, M., Viggiano, A., Viggiano, A., Viggiano, E., Lanza, A., and De Luca, V. (2005). Hyperthermic reactions induced by orexin A: role of the ventromedial hypothalamus. Eur. J. Neurosci. 22, 1169-1175. doi: 10.1111/j.1460-9568.2005. 04309.x

Murata, K. (2020). Hypothetical Roles of the Olfactory Tubercle in Odor-Guided Eating Behavior. Front. Neural Circ. 14:577880. doi: 10.3389/fncir.2020.577 880
Ossowska, K., Karcz, M., Wardas, J., and Wolfarth, S. (1990). Striatal and nucleus accumbens D1/D2 dopamine receptors in neuroleptic catalepsy. Eur. J. Pharmacol. 182, 327-334. doi: 10.1016/0014-2999(90)90291-D

Patel, K. V., Aspesi, A. V., and Evoy, K. E. (2015). Suvorexant: a dual orexin receptor antagonist for the treatment of sleep onset and sleep maintenance insomnia. Ann. Pharmacother. 49, 477-483. doi: 10.1177/1060028015570467

Patel, M., Manning, J. J., Finlay, D. B., Javitch, J. A., Banister, S. D., Grimsey, N. L., et al. (2020). Signalling profiles of a structurally diverse panel of synthetic cannabinoid receptor agonists. Biochem. Pharmacol. 175:113871. doi: 10.1016/ j.bcp.2020.113871

Petrunich-Rutherford, M. L., and Calik, M. W. (2021). Effects of cannabinoid agonists and antagonists on sleep in laboratory animals. Adv. Exp. Med. Biol. 1297, 97-109. doi: 10.1007/978-3-030-61663-2_7

Plaza-Zabala, A., Maldonado, R., and Berrendero, F. (2012). The hypocretin/orexin system: implications for drug reward and relapse. Mol. Neurobiol. 45, 424-439. doi: $10.1007 / \mathrm{s} 12035-012-8255-\mathrm{z}$

Polissidis, A., Galanopoulos, A., Naxakis, G., Papahatjis, D., Papadopoulou-Daifoti, Z., and Antoniou, K. (2013). The cannabinoid CB1 receptor biphasically modulates motor activity and regulates dopamine and glutamate release region dependently. Int. J. Neuropsychopharmacol. 16, 393-403. doi: 10.1017/ S1461145712000156

Rawls, S. M., Cabassa, J., Geller, E. B., and Adler, M. W. (2002). CB 1 Receptors in the Preoptic Anterior Hypothalamus Regulate WIN 55212-2 [(4,5-dihydro-2-methtyl-4(4-morpholinylmethyl0-1-(1-naphthalenylcarbonyl)-6H-pyrrolo[3,2,1ij]quinolin-6-one]-induced Hypothermia. J. Pharmacol. Exp. Ther. 301, 963-968. doi: 10.1124/jpet.301.3.963

Rodríguez de Fonseca, F., Cebeira, M., Ramos, J. A., Martín, M., and FernándezRuiz, J. J. (1994). Cannabinoid receptors in rat brain areas: sexual differences, fluctuations during estrous cycle and changes after gonadectomy and sex steroid replacement. Life Sci. 54, 159-170. doi: 10.1016/0024-3205(94)00585-0

Sahni, V., Engmann, A., Ozkan, A., and Macklis, J. D. (2020). "Chapter 8 Motor cortex connections," in Neural Circuit and Cognitive Development, eds J. Rubenstein, P. Rakic, B. Chen, and K. Y. Kwan (Cambridge: Academic Press), 167-199. doi: 10.1016/B978-0-12-814411-4.00008-1

Struik, D., Sanna, F., and Fattore, L. (2018). The modulating role of sex and anabolic-androgenic steroid hormones in cannabinoid sensitivity. Front. Behav. Neurosci. 12:249. doi: 10.3389/fnbeh.2018.00249

Trivedi, P., Yu, H., MacNeil, D. J., Van Der Ploeg, L. H. T., and Guan, X. M. (1998). Distribution of orexin receptor mRNA in the rat brain. FEBS Lett. 438, 71-75. doi: 10.1016/S0014-5793(98)01266-6

Tseng, A. H., and Craft, R. M. (2001). Sex differences in antinociceptive and motoric effects of cannabinoids. Eur. J. Pharmacol. 430, 41-47. doi: 10.1016/ S0014-2999(01)01267-5

Turski, L., Havemann, U., and Kuschinsky, K. (1984). GABAergic mechanisms in mediating muscular rigidity, catalepsy and postural asymmetry in rats: differences between dorsal and ventral striatum. Brain Res. 322, 49-57. doi: 10.1016/0006-8993(84)91179-x

Valencia Garcia, S., and Fort, P. (2018). Nucleus Accumbens, a new sleep-regulating area through the integration of motivational stimuli. Acta Pharmacol. Sin. 39, 165-166. doi: 10.1038/aps.2017.168

Wakley, A. A., and Craft, R. M. (2011). Antinociception and sedation following intracerebroventricular administration of $\Delta 9$-tetrahydrocannabinol in female vs. male rats. Behav. Brain Res. 216, 200-206. doi: 10.1016/j.bbr.2010.07.037

Walker, J. M., and Hohmann, A. G. (2005). "Cannabinoid mechanisms of pain suppression," in Cannabinoids, ed. R. G. Pertwee (Heidelberg: Springer), 509-554.

Ward, R. J., Pediani, J. D., and Milligan, G. (2011). Heteromultimerization of cannabinoid $\mathrm{CB} 1$ receptor and orexin OX 1 receptor generates a unique complex in which both protomers are regulated by orexin A. Int. J. Biol. Chem. 286, 37414-37428. doi: 10.1074/jbc.M111.287649

Wesson, D. W., and Wilson, D. A. (2011). Sniffing out the contributions of the olfactory tubercle to the sense of smell: hedonics, sensory integration, and more? Neurosci. Biobehav. Rev. 35, 655-668. doi: 10.1016/j.neubiorev.2010.0 8.004

Willie, J. T., Chemelli, R. M., Sinton, C. M., Tokita, S., Williams, S. C., Kisanuki, Y. Y., et al. (2003). Distinct narcolepsy syndromes in orexin receptor-2 and orexin null mice: molecular genetic dissection of non-REM and REM sleep 
regulatory processes. Neuron 38, 715-730. doi: 10.1016/S0896-6273(03)00 330-1

Wiley, J. L., Lefever, T. W., Marusich, J. A., and Craft, R. M. (2017). Comparison of the discriminative stimulus and response rate effects of $\Delta 9$ tetrahydrocannabinol and synthetic cannabinoids in female and male rats. Drug Alcohol Depend. 172, 51-59. doi: 10.1016/j.drugalcdep.2016.11.035

World Health Organization [WHO] (2016). Cannabis. Available Online at: https://www.who.int/teams/mental-health-and-substance- use/alcohol-drugsand-addictive-behaviours/drugs-psychoactive/cannabis [Accessed Oct 1, 2021].

Yamanaka, A., Beuckmann, C. T., Willie, J. T., Hara, J., Tsujino, N., Mieda, M., et al. (2003). Hypothalamic orexin neurons regulate arousal according to energy balance in mice. Neuron 38, 701-713. doi: 10.1016/S0896-6273(03)00331-3

Yazdi, F., Jahangirvand, M., Pirasteh, A. H., Moradi, M., and Haghparast, A. (2015). Functional interaction between $\mathrm{OX} 2$ and CB1 receptors in the ventral tegmental area and the nucleus accumbens in response to place preference induced by chemical stimulation of the lateral hypothalamus. Pharmacol. Biochem. Behav. 139, 39-46. doi: 10.1016/j.pbb.2015.10.012

Yoshimichi, G., Yoshimatu, H., Masaki, T., and Sakata, T. (2001). Orexin-A regulates body temperature in coordination with arousal status. Exp. Biol. Med. 226, 468-476. doi: 10.1177/15353702012260 0513

Zagzoog, A., Brandt, A. L., Black, T., Kim, E. D., Burkart, R., Patel, M., et al. (2021). Assessment of select synthetic cannabinoid receptor agonist bias and selectivity between the type 1 and type 2 cannabinoid receptor. Sci. Rep. 11:10611. doi: 10.1038/s41598-021-90167-w

Zagzoog, A., Mohamed, K. A., Kim, H. J. J., Kim, E. D., Frank, C. S., Black, T., et al. (2020). In vitro and in vivo pharmacological activity of minor cannabinoids isolated from Cannabis sativa. Sci. Rep. 10:20405. doi: 10.1038/s41598-02077175-y

Zanettini, C., Panlilio, L. V., Alicki, M., Goldberg, S. R., Haller, J., and Yasar, S. (2011). Effects of endocannabinoid system modulation on cognitive and emotional behavior. Front. Behav. Neurosci. 5:57. doi: 10.3389/fnbeh.2011. 00057

Zinchuk, V., and Zinchuk, O. (2008). Quantitative colocalization analysis of confocal fluorescence microscopy images. Curr. Protoc. Cell Biol. 39, 1-4. doi: 10.1002/0471143030.cb041 9 s39

Conflict of Interest: The authors declare that the research was conducted in the absence of any commercial or financial relationships that could be construed as a potential conflict of interest.

Publisher's Note: All claims expressed in this article are solely those of the authors and do not necessarily represent those of their affiliated organizations, or those of the publisher, the editors and the reviewers. Any product that may be evaluated in this article, or claim that may be made by its manufacturer, is not guaranteed or endorsed by the publisher.

Copyright (C) 2021 Kim, Zagzoog, Smolyakova, Ezeaka, Benko, Holt and Laprairie. This is an open-access article distributed under the terms of the Creative Commons Attribution License (CC BY). The use, distribution or reproduction in other forums is permitted, provided the original author(s) and the copyright owner(s) are credited and that the original publication in this journal is cited, in accordance with accepted academic practice. No use, distribution or reproduction is permitted which does not comply with these terms. 